\title{
Indígenas, Borbones y enclaves coloniales. Las relaciones interétnicas en el fuerte San José durante su primera década de funcionamiento (Chubut, 1779-1789)
}

Indigenous, Bourbons, and colonial settlements. Interethnic relations at San José Fort during its first decade (Chubut, 1779-1789)

\section{Silvana Buscaglia}

\section{(2) OpenEdition}

\section{Journals}

Electronic version

URL: http://journals.openedition.org/corpusarchivos/1383

DOI: 10.4000/corpusarchivos. 1383

ISSN: 1853-8037

\section{Publisher}

Diego Escolar

\section{Electronic reference}

Silvana Buscaglia, «Indígenas, Borbones y enclaves coloniales. Las relaciones interétnicas en el fuerte San José durante su primera década de funcionamiento (Chubut, 1779-1789) », Corpus [En línea], Vol 5, No 1 | 2015, Publicado el 30 junio 2015, consultado el 10 diciembre 2020. URL : http://

journals.openedition.org/corpusarchivos/1383; DOI : https://doi.org/10.4000/corpusarchivos.1383

This text was automatically generated on 10 December 2020. 


\section{Indígenas, Borbones y enclaves coloniales. Las relaciones} interétnicas en el fuerte San José
durante su primera década de
funcionamiento (Chubut, 1779-1789)

Indigenous, Bourbons, and colonial settlements. Interethnic relations at San José Fort during its first decade (Chubut, 1779-1789)

\section{Silvana Buscaglia}

\section{EDITOR'S NOTE}

Fecha de recepción del original: 25/08/2014

Fecha de aceptación para publicación: 10/02/2015

Fuentes inéditas

Argentina. Archivo General de la Nación. Sala VII, Biblioteca Nacional, Legajo 193. Sala IX, Legajos: 16-3-2, 16-3-6, 16-3-9, 16-3-10, 16-3-16, 16-4-2, 16-4-3, 16-4-4, 16-4-5, 16-4-6, 16-4-11, 16-4-12, 16-5-1. Sala X, Legajo: 2-3-15. Sala XIII, Legajos: 34-10-5, 26-6-6, 31-1-5. Brasil. Fundação Biblioteca Nacional. MS-508 (40) Doc.1164 "Diario de la Expedición de Don José de Salazar al Puerto de San José, 1783".

España. Archivo General de Indias, Audiencia de Buenos Aires, Legajos: 326, folios 601-798, carta $n^{\circ} 210$.

España. Archivo Histórico de Madrid, sección Estado, legajo 2316 “Diario de la expedición del mando del Comisario Superintendente Don Juan de la Piedra que con 4 embarcaciones armadas en guerra y 114 hombres de Tropa de Tierra con sus respectivos Oficiales, sale del Puerto de Montevideo el 15 de diciembre de 1778 en busca 
del nombrado Bahía Sin Fondo en la costa Patagónica debiendo después de dejar allí hecho un establecimiento seguir a formar otro al Puerto de San Julián".

Agradecimientos

A los evaluadores anónimos cuyos comentarios, sugerencias y aportes han contribuido a mejorar la calidad del presente trabajo. Al equipo editorial de la revista Corpus por la oportunidad de publicar en la misma. Agradezco a la Dra. Julieta Gómez Otero, a la Dra. Marcia Bianchi Villelli, a la Dra. Victoria Pedrotta, a la Lic. Jimena Alberti, a Sabrina Carelli y Laura Starópoli, quienes de distintas maneras han contribuido para la elaboración del presente artículo. Al profesor Raúl Mandrini por su inestimable orientación y generosidad. Agradezco al Lic. Bruno Sancci por su colaboración en la búsqueda y obtención en archivos españoles de algunos de los documentos históricos analizados en el presente trabajo.

Los resultados de las investigaciones volcados en el presente trabajo han sido generados en el marco de los proyectos "Relaciones Interétnicas en península Valdés (Chubut, siglos XVIII-XIX). Una perspectiva histórica y arqueológica" PIP 0183, CONICET, 2011-201, bajo la dirección de la Dra. S. Buscaglia y el "Proyecto Paisajes Coloniales en Patagonia. Los Asentamientos de península Valdés (1779-1810)” PICT 2010-050, FONCYT, 2011-1012, bajo la dirección de la Dra. M. Bianchi Villelli.

\section{Introducción}

1 La problemática de la colonización española de la costa patagónica a fines del siglo XVIII ha sido objeto de un exhaustivo y diverso tratamiento en la literatura histórica, etnohistórica $\mathrm{y}$, más recientemente, arqueológica. Sin embargo, de los tres asentamientos principales que integraron el plan de poblamiento: el fuerte Nuestra Señora del Carmen (Carmes de Patagones, provincia de Buenos Aires), la Nueva Colonia y fuerte de Floridablanca (puerto San Julián, provincia de Santa Cruz) y el fuerte San José (península Valdés, provincia de Chubut), este último ha sido el más postergado en el marco de dichas investigaciones, particularmente aquellas provenientes del ámbito académico. Esta situación comenzó a revertirse a partir del año 2010, cuando se inició el proyecto "Primeros abordajes arqueológicos al fuerte San José y Manantiales Villarino, península Valdés, Chubut (1779-1810)"', el cual se propuso discutir desde la perspectiva de la arqueología histórica la conformación del paisaje colonial en península Valdés, atendiendo a la intersección de estrategias coloniales e indígenas y contribuir de este modo a ampliar la discusión sobre el proceso de colonización de la costa patagónica.

2 Uno de los aspectos más relegados y peor tratados ${ }^{2}$ en el abordaje tradicional al fuerte San José (ver críticas en Bianchi Villelli, 2011, 2012 y 2014), ha sido la problemática de las relaciones interétnicas. Se trata de un tema completamente marginado en el abordaje historiográfico tradicional, que puso el acento únicamente en el conflictivo episodio que marcó el fin de los establecimientos españoles en península Valdés. La consecuencia natural de este sesgo fue una invisibilización de las poblaciones indígenas y las relaciones interétnicas a lo largo de los 31 años de existencia del fuerte, simplificando una realidad por demás compleja. Sin embargo, más grave aún ha sido la representación de los indígenas como "bárbaros y salvajes", sin discutir críticamente la evolución de las relaciones interétnicas a lo largo del tiempo ni las causas posibles que llevaron a una relación conflictiva con la población hispano-criolla del fuerte (Entraigas, 1960 y 1968; Laonel et al., 1974; De Paula, 1984; Destéfani, 1984; Dumrauf, 
1992; Barba Ruiz, 2000 y 2009)3. Como resultado, el etnocentrismo que subyace a los abordajes y representaciones mencionados, se repite una y otra vez en tanto estrategia estigmatizante, cuya finalidad no es otra que enaltecer y legitimar las "gestas colonizadoras españolas" de Chubut, en ausencia de una discusión crítica respecto del proceso colonizador.

3 Frente a este estado de la cuestión, se hacía imperativo no solo llenar los vacíos respecto a las relaciones interétnicas en el fuerte San José, sino por sobre todo discutir las representaciones colonialistas de las mismas, de manera de comprenderlas en términos de su complejidad y desde una perspectiva multidireccional del contacto cultural, donde fuera posible romper con la dicotomía colonizadores-dominantescivilizados / colonizados-dominados-salvajes.

Considero que el primer paso para alcanzar estos objetivos es contextualizar social, temporal y espacialmente las relaciones interétnicas en península Valdés, de manera de visibilizar a los indígenas, sus prácticas e interacciones con los establecimientos coloniales. Dicho abordaje se integra a una investigación más amplia, centrada en la discusión de la agencia indígena para alterar o transformar las condiciones de la vida cotidiana de los asentamientos españoles establecidos en la costa patagónica a fines del siglo XVIII (Buscaglia, 2010, 2011a y b, 2012) .

5 Dentro de este marco general me propongo discutir en este trabajo la forma en que se estructuraron las relaciones interétnicas en el fuerte San José durante su primera década de funcionamiento, poniendo el foco en los relatos históricos, pero sin perder de vista la evidencia arqueológica. En particular, me interesa analizar las relaciones entre indígenas y la población hispano-criolla en función de las características propias de un contexto fundacional así como de las políticas indígenas y borbónicas virreinales respecto al contacto. Este objetivo surge de un interés por explorar las nuevas condiciones emergentes a partir de la instalación colonial en la península y una ausencia casi total de información respecto a la configuración de las relaciones interétnicas en este escenario particular ${ }^{5}$.

6 Si bien el análisis de las fuentes históricas primarias sugiere un cuadro de conflictividad entre la población hispano criolla del fuerte San José y la indígena a lo largo de sus 31 años de duración, es necesario evitar supuestos a priori e indagar cómo fue la dinámica interétnica en la práctica, de manera de complejizar la imagen transmitida por el discurso colonial y discutir su falta de problematización desde el abordaje historiográfico tradicional.

Uno de los primeros aspectos que llamó mi atención al abordar las relaciones interétnicas en el contexto del fuerte San José fue el notable contraste con los casos del fuerte Nuestra Señora del Carmen y, por sobre todo, la colonia de Floridablanca (Buscaglia s/f, 2011a y b, 2012)6. La comparación con los otros dos casos llevó a preguntarme cómo se insertó el fuerte San José en la dinámica interétnica en Patagonia. ¿Incidió en ello su carácter fundacional? ¿Cómo repercutieron en este contexto particular las políticas de contacto impulsadas por los Borbones en Patagonia? ¿Cuál fue la significación de los establecimientos coloniales en el marco de las dinámicas culturales, económicas, políticas y territoriales de las poblaciones indígenas, entre otras cosas? ¿Es posible que desde el plano discursivo solo se estuviese mostrando una faceta de las relaciones interétnicas? ¿Hubo margen para otras formas de interacción? 
Para poder empezar a responder a algunos de estos interrogantes, resultó necesario establecer un recorte temporal acotado a la primera década de funcionamiento de los establecimientos de península Valdés (1779-1789). La fundamentación de dicho recorte descansa por un lado en la necesidad de profundizar en los distintos momentos del lapso total de duración de estos asentamientos, aspecto que ha sido relegado en el abordaje historiográfico tradicional sobre el caso, y que implicaba prácticamente comenzar desde cero las investigaciones (Entraigas, 1960 y 1968; De Paula, 1984; Destéfani, 1984; Dumrauf, 1992; Barba Ruiz, 2000 y 2009). Por otro lado, un recorte temporal se hace necesario a los efectos no solo de presentar en detalle información histórica inédita hasta el momento, sino también para comprender en profundidad la forma en que se estructuraron las relaciones interétnicas en este escenario en particular, así como sus variaciones a lo largo del tiempo y el espacio -en lugar de homogeneizarlas- en el contexto del proceso colonizador de la Patagonia a fines del siglo XVIII.

9 Por último, el abordaje de las relaciones interétnicas desde la dimensión documental, contempló, por un lado la confrontación crítica de distintos tipos de fuentes escritas éditas e inéditas -cartas, informes, diarios, entre otros-, y por otro una aproximación a los registros escritos más allá de su contenido, interpretando los silencios, las contradicciones, las ambigüedades, las grietas y las inconsistencias en el discurso oficial. En estos espacios es donde considero que se hacen visibles y adquieren voz aquellos actores y prácticas que no dejaron evidencia visual o escrita sobre sí mismos, quedando en cierta forma al margen del proceso de elaboración del registro histórico (Scott, 1990; Mallon, 1994, Spivak, 1994; Hall, 1999, entre otros). A continuación se presenta una breve caracterización del fuerte San José, para luego desarrollar el contexto en el cual se habrían enmarcado las relaciones interétnicas.

\section{Los establecimientos coloniales de península Valdés}

En publicaciones previas ya se han presentado con detalle tanto las características del plan de colonización español de la costa patagónica a fines del siglo XVIII como los detalles referidos al fuerte San José (Senatore, 2007; Bianchi Villelli, 2009; Buscaglia, 2012; Buscaglia y Bianchi Villelli, 2012; Buscaglia et al., 2012; Bianchi Villelli et al., 2013, entre otros), razón por la cual en este trabajo tan solo haré una breve referencia a los mismos.

11 La ocupación española de la península Valdés a fines del siglo XVIII representa el primer intento de colonización del área por parte de europeos (Figura 1). El fuerte San José fue el primero de los establecimientos en fundarse a principios de 1779, sobre la costa sudeste del golfo homónimo (península Valdés, Chubut). Allí se estableció un pequeño núcleo poblacional que habitó un asentamiento de carácter precario hasta que se produjo el abrupto final del mismo.

12 Casi de manera simultánea se crea el Puesto de la Fuente, un asentamiento de carácter complementario al fuerte San José, situado a unos $30 \mathrm{~km}$ del mismo - unas 5 leguas castellanas ${ }^{7}-$, sobre el ángulo sudoeste de la denominada Salina Grande (estancia Manantiales, península Valdés, provincia de Chubut) (ver Figura 1). La razón de la creación del Puesto de la Fuente fue el descubrimiento de fuentes de agua dulce para el 
abastecimiento de la población y los animales ${ }^{8}$. Asimismo, la cercanía a la salina implicó el aprovechamiento económico de la misma. Con el tiempo este establecimiento se convirtió en un puesto ganadero y salinero, proyecto que originalmente fuera propuesto por Juan de la Piedra y retomado por Basilio Villarino luego de que el primero fuese separado de su comisión en la costa patagónica (Gorla, 1983). Al respecto, es interesante mencionar la observación que hiciera en su diario el coronel Luis Jorge Fontana ([1886] 1999) referida a la particular abundancia y calidad de las pasturas en la península. Esta condición será aprovechada por las poblaciones indígenas que circulaban por la misma, durante y luego de la destrucción del fuerte.

Figura 1. Localización del fuerte San José y el Puesto de la Fuente (península Valdés, provincia de Chubut).
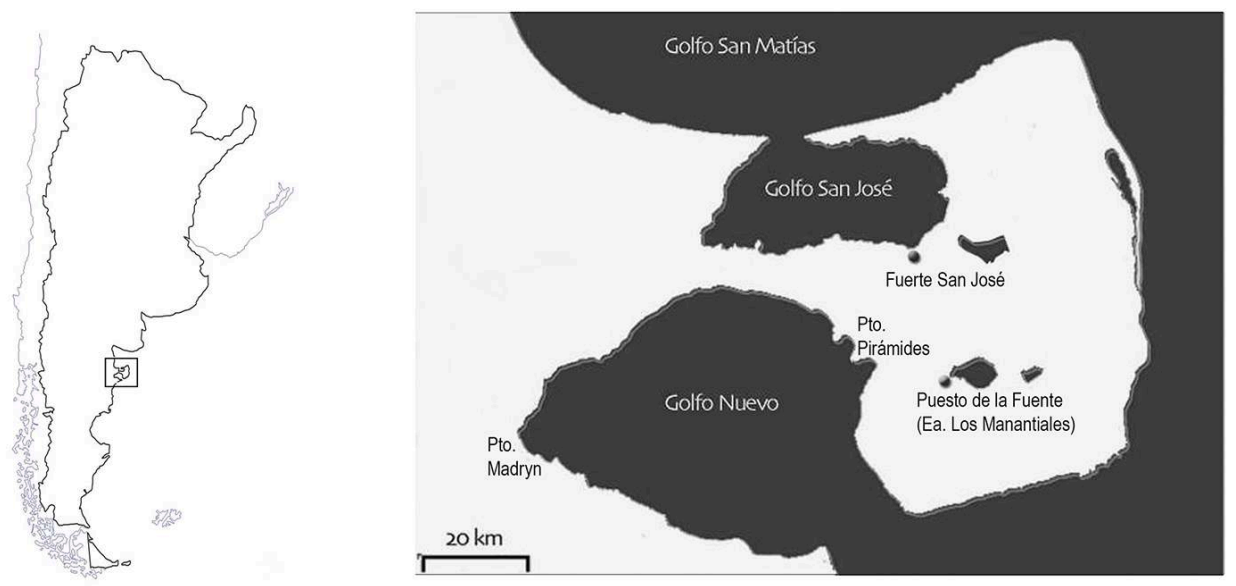

13 Así, sobre la base del descubrimiento de nuevos recursos y posibilidades la funcionalidad del fuerte San José se fue definiendo en la práctica (Buscaglia y Bianchi Villelli, s/f). En 1783 el teniente de infantería don José de Salazar señalaba en su diario las bondades que presentaba el puerto donde se hallaba instalado el fuerte en su condición de escala para las embarcaciones que seguían su paso hacia el sur', su potencial en cuanto a la pesca de cetáceos -en un mes se arponearon 50 ballenas-, la excelente calidad de las salinas, la disponibilidad de agua dulce en abundancia incluso para realizar cultivos -mencionando la existencia de una "huertecilla" en el área de los manantiales ${ }^{10}$.

Más allá de una funcionalidad originalmente defensiva ${ }^{11}$ (Bianchi Villelli, 2011, 2013), el fuerte San José se fue transformando con el correr del tiempo en un enclave económico cuyas funciones a lo largo de sus 31 de años de funcionamiento gravitaron en torno a proyectos no del todo bien implementados de explotación pesquera y ballenera, y en menor medida lobera (Martínez de Gorla, 2004). Mayor éxito y sistematicidad tuvo la explotación salinera así como la ganadera (Gorla, 1983).

Los asentamientos coloniales de península Valdés fueron gobernados por distintos comandantes a lo largo de su historia de ocupación, sucediéndose aproximadamente catorce solamente en el período que nos atañe ${ }^{12}$. La población de ambos asentamientos habría sido predominantemente masculina ${ }^{13}$ y variable en su número, aproximadamente entre 9 y 150 personas, todas ellas personal militar, funcionarios, capellanes, peones, presidiarios y ocasionalmente marinos. El fuerte San José dependió administrativa y económicamente del fuerte Nuestra Señora del Carmen, lo que en 
muchas ocasiones lo situó en una posición de extrema vulnerabilidad, particularmente por los períodos frecuentes de desabastecimiento que debió afrontar.

Si bien los asentamientos en península Valdés lograron sobrevivir a la Real Orden del $1^{\circ}$ de agosto de 1783 en la que se disponía el abandono de los poblados patagónicos, 27 años después la Primera Junta de Gobierno dispuso el 10 de agosto de 1810 el traslado de la guarnición a Carmen de Patagones. Sin embargo, tres días antes de producirse el mismo -entre el 7 y 8 de agosto de ese año- tanto la fortificación sobre la costa como el asentamiento de la salina habrían sido atacados e incendiados por indígenas, produciéndose la muerte de 15 hombres, mientras que otros 19 fueron tomados cautivos. De estos últimos, cinco logaron huir y dar testimonio de lo sucedido en la península un mes más tarde, cuando llegaron al fuerte Nuestra Señora del Carmen (Entraigas, 1960 y 1968; De Paula, 1984; Destéfani, 1984; Dumrauf, 1992). En el documento original ${ }^{14}$ que se encuentra en el Archivo General de la Nación, los sobrevivientes no dan cuenta de las causas del ataque ni de la parcialidad étnica que lo encabezó $^{15}$. Asimismo, todas las versiones posteriores ${ }^{16}$ sobre el hecho difieren en las causas de la agresión y otros detalles relacionados con la misma ${ }^{17}$.

Dada la diversidad de versiones ${ }^{18}$ y la ambigüedad que reina sobre las mismas respecto a las causas que motivaron el abrupto final del fuerte, así como la escasa información histórica de primera mano obtenida hasta el momento, considero que el "malón" es un hecho que necesita ser corroborado, en lugar de asumido, a partir de la integración de una mayor cantidad de líneas independientes de evidencia y una perspectiva diacrónica que permita evaluar la dinámica interétnica a lo largo del tiempo y el espacio para comprender las causas del ataque. Ello requiere de una discusión crítica y de una profundización en el análisis de las fuentes primarias y secundarias, así como la complementación de evidencia arqueológica recuperada a lo largo de las investigaciones.

\section{El carácter fundacional del fuerte San José}

El carácter fundacional y la inestabilidad son condiciones que se encuentran estrechamente vinculadas, sobre todo en contextos alejados de los centros de poder como fue el caso del fuerte San José. Considero que ambos aspectos juegan un rol central en el proceso de estructuración social (Giddens, 1995) y, sobre todo, en el carácter que pueden adoptar las relaciones sociales entre los diferentes actores que integran o se vinculan a una empresa de poblamiento, en nuestro caso la población hispano-criolla y la indígena.

Por un lado, nos encontramos ante una sociedad que comienza a re-estructurarse desde cero, que carece de profundidad o de arraigo histórico de ciertos principios organizacionales y de referentes institucionales sólidos. Por lo tanto, en un contexto fundacional es esperable que para el arraigo de tales principios y el fomento de prácticas acorde a los mismos en el seno de la sociedad sea preciso el desarrollo, la reproducción y el reforzamiento de ciertos mecanismos que sirvan de marco de legitimación del poder y, por ende, de los intereses de la empresa de poblamiento.

Por otro lado, existen toda una serie de dificultades inherentes a los contextos de colonización iniciales que comprenden desde la adaptación a un nuevo entorno social y natural, hasta el aislamiento, los problemas de abastecimiento, la ruptura real o imaginaria con los referentes metropolitanos, entre otras cosas. Dadas estas 
condiciones, el conflicto -interno y externo- siempre es una posibilidad latente y compleja a resolver en caso de manifestarse, debido a la ausencia de autoridades inmediatas a las cuales recurrir, la incomunicación, el reducido número de tropa, entre otros aspectos. Todos estos factores se conjugan para imprimirles a las colonias en sus fases iniciales, un alto componente de inestabilidad e incertidumbre.

\subsection{Las condiciones que hicieron del fuerte San José un contexto vulnerable}

21 El fuerte San José se encontraba en una situación de fuerte aislamiento geográfico y social, debido a su emplazamiento en la península y distanciado no solo de la capital virreinal sino también de las poblaciones de Nuestra Señora del Carmen y Floridablanca. La comunicación más rápida y factible era a través de la vía marítima, no solo porque el conocimiento del interior de la Patagonia no se encontraba muy desarrollado, sino también por el peligro de un eventual enfrentamiento con poblaciones indígenas.

En el caso del fuerte San José el análisis de la documentación histórica ha permitido establecer que los principales referentes del poder en el fuerte, es decir los comandantes, carecieron de una capacidad de mando realmente efectiva en la práctica. Ello se vio agravado por el sistema anual de relevos que no posibilitaba el afianzamiento de la autoridad ${ }^{19}$, la escasez de tropa - sobre todo experimentada- y la falta de referentes materiales de poder (Foucault, 2001 [1976]), expresados por ejemplo en la arquitectura y la organización del espacio, como se mostrará más adelante.

De manera similar a muchos emprendimientos coloniales, el fuerte San José no estuvo libre de contratiempos a lo largo de toda su historia ocupacional. El fantasma del desabastecimiento fue en efecto una realidad que signó en ocasiones la vida del fuerte ${ }^{20}$. A ello se sumaba, dadas las pésimas condiciones habitacionales, el deterioro de los alimentos almacenados a causa de las condiciones climáticas y las ratas, como se refiere a continuación: "Este almacén está muy inundado de ratas pues es el primero que se hizo, y se comen todas las harinas y minestras, y cuanto en él se mete [...]" ${ }^{21}$.

Frente a la irregularidad en el abastecimiento y el mantenimiento de las provisiones, la alternativa fue la complementariedad económica mediante el aprovechamiento de los recursos locales. En ello los indígenas podrían haber jugado un rol fundamental, no solo en el suministro de información sobre los mismos sino mediante el intercambio y el abastecimiento directo, tal como se buscó fomentar desde las políticas borbónicas como veremos más adelante. Sin embargo, esta no parece haber sido la norma en el caso de San José, a diferencia de las colonias de Nuestra Señora del Carmen y Floridablanca (Gorla, 1983; Nacuzzi, 2002, 2005; Luiz, 2006a y b; Buscaglia, 2011a y b, 2012, entre otros).

Las enfermedades y las muertes son otro gran flagelo que ha caracterizado la historia de los asentamientos coloniales, sobre todo durante su primera etapa de funcionamiento. La insalubridad de la población, y máxime si esta tiene consecuencias mortales ha sido una de las principales causas para el desarrollo de conflictos e inestabilidad. De manera similar al caso de Floridablanca, el azote del escorbuto puso en peligro la continuidad de la empresa de poblamiento en península Valdés durante sus momentos iniciales, ocasionando la muerte de 28 personas (Viedma, 1969 [1784]) ${ }^{22}$. 
factor que puede contribuir al desarrollo de condiciones de inestabilidad en los contextos fundacionales se relaciona con la precariedad de los espacios de habitación destinados al alojamiento de la población. En general estos espacios eran poco adecuados para hacer frente a las inclemencias climáticas, de carácter reducido y compartido por varios individuos o grupos familiares no necesariamente emparentados. En el caso del fuerte San José esta fue una situación que prevaleció a lo largo de todo su lapso de ocupación, ya que al menos hasta 1800 se continúan registrando en la documentación histórica pedidos de materiales y albañiles para superar las condiciones de precariedad ${ }^{23}$. El fuerte, si es que puede denominárselo como tal, habría estado conformado mayormente por tiendas de palos y cueros y en menor medida estructuras de adobe con techos de paja. Es importante señalar que las intervenciones arqueológicas han permitido corroborar, por lo menos hasta el momento, la precariedad del establecimiento, donde a pesar de los 31 años de ocupación, existe una baja obstrusividad y escasas evidencias de restos asociados a edificaciones más duraderas -i.e. restos de adobes, tapia, tejas, ladrillos- (Bianchi Villelli et al., 2013; Buscaglia y Bianchi Villelli, 2012; Buscaglia, et al. 2012) (Figura 2).

Figura 2. a) Vista del emplazamiento del fuerte San José, b) excavaciones arqueológicas y c) cerámica española recuperada durante las investigaciones (Fotos: Marcia Bianchi Villelli y Silvana Buscaglia).

(a)
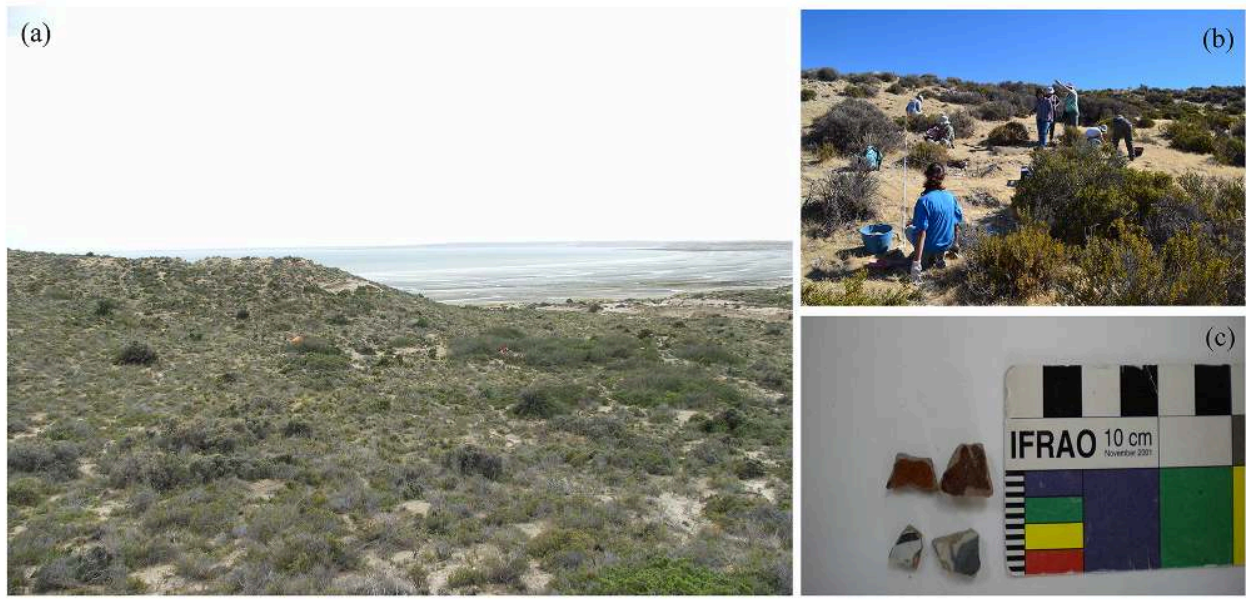

Tomadas en su conjunto, estas condiciones habrían hecho del fuerte San José un contexto extremadamente vulnerable e inestable. Ahora bien, si estas fueron algunas de las muchas condiciones que prevalecieron en el contexto de las colonias y fuertes patagónicos, entonces es válido preguntarse cómo incidieron las mismas en la estructuración de las relaciones interétnicas. Dada la vulnerabilidad del asentamiento, ¿se habría incentivado un trato pacífico con las poblaciones locales con el fin de contar con su ayuda y minimizar el riesgo de conflicto, como ocurrió en el caso de Floridablanca por ejemplo? ¿Habrían estado interesadas las mismas en un acercamiento al puesto colonial? o ¿representó la instalación del fuerte una intrusión a un territorio por lo menos valorado en función de la disponibilidad de ciertos recursos críticos? 


\section{La política del contacto en el virreinato del Río de la Plata}

Dadas las condiciones inherentes a los contextos fundacionales, las empresas colonizadoras no disponían de demasiadas alternativas entre las cuales elegir, situándose en los extremos la política ofensiva o la negociación con las poblaciones originarias. En el marco del proyecto de colonización española de la costa patagónica, esta última fue la alternativa elegida por varios motivos, que van desde los fundamentos ideológicos del plan hasta razones de índole más pragmática, aunque con distintos matices en la práctica. Sin embargo, el contexto que nos atañe fue un contexto de claro predominio y superioridad de las poblaciones indígenas por sobre los colonizadores.

La política colonial del siglo XVIII en relación a las poblaciones indígenas de Pampa y Patagonia se distingue claramente de la de siglos precedentes y siguientes como consecuencia de los cambios introducidos por las reformas borbónicas. Recordemos que una de las prioridades de las mismas fue la reorganización territorial y administrativa de las posesiones de la Corona en el Atlántico Sur (Lynch, 1992; Sarrailh, 1992). En este contexto era insoslayable una política en relación a los indígenas que habitaban en la periferia de los centros de poder, sobre todo aquella que se extendía hacia la frontera sur de la capital del virreinato.

Los estudios de Lidia Nacuzzi (2005) y María Teresa Luiz (2006a) sobre la dinámica interétnica en el contexto de la Patagonia de fines del siglo XVIII constituyen los análisis más completos realizados hasta la fecha sobre esta problemática en el marco de la historia y la etnohistoria ${ }^{24}$. De acuerdo con Luiz (2006a), dos fueron los factores que marcaron el carácter particular a las relaciones interétnicas en el marco de las políticas borbónicas. El primero estará relacionado con las características propias de las sociedades indígenas que habitaban los confines meridionales del imperio y su relación con la sociedad virreinal, por cuanto la estructura misma de estas sociedades -en su mayor parte cazadores-recolectores semi-nómades y dispersos, con excepción de los mapuches-dificultará su reducción.

El segundo factor estará dado por la inestabilidad de las fundaciones hispanas situadas en áreas periféricas a los centros de poder, donde la posibilidad de una relación hostil con las poblaciones locales no representaba una alternativa posible, como fue desarrollado más arriba. Ello determinará que las relaciones de poder entre los agentes coloniales y los indígenas se estructuren de una manera específica y diferente en comparación a otras áreas bajo el dominio hispánico. Si bien esta fue una premisa de partida, con excepción del caso de Floridablanca, las relaciones entre las poblaciones indígenas y los establecimientos se volvieron hostiles y violentas en reiteradas ocasiones, como lo ejemplificaremos para el caso del fuerte San José durante su primera década de funcionamiento.

\subsection{Las relaciones interétnicas en el marco de las políticas borbónicas e indígenas}

32 Así, desde el principio se procuró que el contacto inicial con las poblaciones locales se realizara en forma pacífica, privilegiando un trato benevolente y tolerante hacia los 
indígenas, aun en caso de presentarse hostilidades. El Oficio del 3 de noviembre de 1778 del Virrey Vértiz muestra claramente esta política en el marco de las instrucciones dadas para la fundación de los establecimientos patagónicos:

Si al arribo a la costa, o Bahías referidas se presentaren algunos Indios, se les tratará con el mayor cariño y persuadirá dejen a distancia larga las Armas, agasajándolos con las bujerías, y que lleva para este fin; esmerándose mucho en acariciar las criaturas en presencia y ausencia de sus Padres, y prohibiendo absolutamente bajo graves penas, no sólo el daño que se les hiciere, y que habrá de castigarse a su vista, sino también el que con pretexto alguno traten con los Indios otras gentes que los Eclesiásticos o sujetos, que determinadamente destine, y los que pondrán todo su cuidado en persuadirles a la paz, y en hacerles entender que la intención de poblar allí es de enseñarles a conocer a Dios y su Santa Ley para que se salven, y que también el tener amistad con ellos, y no para hacerles mal, ni quitarles sus haciendas procurando por todos los suaves y buenos medios posibles, que el establecimiento se haga con su paz y consentimiento; pero si no obstante todo este buen trato que se encarga, se obstinaren en contradecirlo, no por esto ha de suspenderse, y aun podrá llegar el caso de ser necesario ahuyentarlos, y también de que el rigor los contenga siempre, que poniendo estorbos a la pronta práctica de la intención de S. M. precisen a estos procedimientos en que ha de obrarse con el mejor pulso y consideración [...]. ${ }^{25}$

Sin embargo, es necesario destacar que Vértiz era ambivalente en cuanto a la relación con los indígenas. Si bien, posiblemente acatando órdenes reales, impulsó una política de tolerancia, al mismo tiempo los consideró como un peligro que debía combatirse, como se refleja en la memoria escrita al término de su mandato ${ }^{26}$.

La política borbónica del contacto tuvo dos objetivos fundamentales (Weber, 1998; Operé, 2001; Quijada, 2002). En primer lugar, poner freno a los malones que las poblaciones indígenas efectuaban sobre los establecimientos coloniales y criollos, mediante la fijación de fronteras, tema ampliamente tratado en la literatura histórica, etnohistórica y arqueológica (ver por ejemplo Mandrini, 1993, 1997; Zusman, 1999; Mayo, 2000; Operé, 2001; Quijada, 2002; Bagaloni, 2006, Luiz, 2006a y b; Pedrotta y Bagaloni. 2006, entre muchos otros). En segundo lugar, asegurarse su buena voluntad y lealtad. En ello pesaba por un lado el temor de que se convirtieran en aliados de otras potencias extranjeras, siendo una de las preocupaciones de España en este período el avance británico y portugués sobre sus posesiones en el sur del continente americano. Por otro lado, fue importante el mantenimiento de lazos comerciales y de intercambio con los grupos locales con el fin de asegurar la continuidad de la empresa de poblamiento. Recordemos que las comunidades indígenas fueron las mayores proveedoras principalmente de ganado vacuno y equino para los establecimientos de Pampa y Patagonia - lo cual retroalimentaba el sistema de malones-, a los que se sumaban otras clases de alimentos y bienes (Gorla, 1983; Mandrini, 1987; Palermo, 1989; Operé, 2001; Nacuzzi, 2005; Luiz, 2006a, entre otros). Como se mostrará en este trabajo, en el caso del fuerte San José ninguno de los dos objetivos mencionados al principio de este párrafo fue alcanzado, al menos en la primera década de funcionamiento del asentamiento.

Con respecto a la evangelización de las poblaciones locales, si bien hubo un intento inicial para la fundación de misiones en la costa patagónica en la primera mitad del siglo XVIII con la expedición de los jesuitas Cardiel, Quiroga y Strobel (Lozano, 1972 [1745]), más tarde esta perderá peso quizás como consecuencia de la expulsión de la orden y el carácter más secular de las políticas borbónicas ${ }^{27}$. El perfil evangelizador de 
la empresa colonizadora fue variable entre los distintos establecimientos. En los casos de Floridablanca y el fuerte San José, es un tema que prácticamente no aparece mencionado en la documentación histórica, a diferencia por ejemplo del fuerte Nuestra Señora del Carmen. Lo cual muestra una vez más el carácter variable del contacto en función de la particularidad de los escenarios, protagonistas y estrategias.

\subsubsection{El contacto como negociación} Patagonia de fines del siglo XVIII fue un proceso complejo, tanto a nivel sincrónico como diacrónico. En términos generales se caracterizó por relaciones pacíficas, pero en el marco de un delicado equilibrio que a veces solía romperse con facilidad. En este contexto la negociación y la ambivalencia en las relaciones interétnicas habrían sido el denominador común, y para su comprensión se hace imperativo atender a las condiciones particulares de los contextos en los que tuvo lugar la interacción, como lo desarrollamos a continuación.

Durante el período virreinal fueron moneda corriente los pactos y las alianzas que garantizaban la paz y la ayuda mutua -en caso por ejemplo de enfrentamientos con otras parcialidades enemigas ${ }^{28}-$, y donde se jugaban condiciones e intereses específicos de ambas partes (Briones y Carrasco, 2000; Quijada, 2002; Nacuzzi, 2002 y 2005, entre otros) ${ }^{29}$. Característico de este momento será también el afianzamiento de lazos comerciales entre las comunidades hispano-criollas y las indígenas de Pampa y Patagonia -tanto andina como extraandina-, quienes estaban incorporadas ya a los circuitos comerciales de la colonia, tal como lo refleja Marta Bechis en su prólogo a "Identidades Impuestas..." de Lidia Nacuzzi:

La fundación de Carmen de Patagones en 1779 llegaba en un buen momento para los indígenas nordpatagónicos. Con esa fundación se completaba el cuadrante Buenos Aires, Concepción, Valparaíso, Carmen de Patagones que rodeó el área auracopampeana. Una nueva boca de comercio se abría. Para los tehuelches del sur, los establecimientos de la costa patagónica, significaban una novedad. Para los tehuelches del norte, que pertenecían a la sub-área del sur de las llanuras, fue una nueva y más cercana oportunidad [...] (Bechis en Nacuzzi, 2005, p.13).

En cuanto a los tehuelches que dominaban el territorio de San Julián (provincia de Santa (ruz) por ejemplo, disponemos de referencias históricas acerca de movimientos estacionales realizados hacia el norte con el fin de intercambiar con otras comunidades indígenas y con los establecimientos Nuestra Señora del Carmen y San José30. Es importante destacar aquí que fue variable la forma en que se estructuraron las relaciones interétnicas entre un mismo grupo indígena y cada uno de los asentamientos que formaron parte del proyecto de poblamiento de la costa patagónica. A diferencia del caso de Floridablanca, la relación de los tehuelches de San Julián con los otros dos poblados no se describe como pacífica (Buscaglia, 2011a y b, 2012 y s/f).

El sistema de dádivas implementado por el gobierno colonial para asegurarse la lealtad y colaboración de los indígenas, principalmente de sus caciques, también contribuirá a reforzar los lazos de interdependencia y complementariedad (Luiz, 2006a y b; Quijada, 2002). Ello ha sido constatado tanto en el caso del fuerte Nuestra Señora del Carmen como en Floridablanca, donde esta política fue muy clara en función del suministro de raciones mensuales a los indígenas, en las que se incluían víveres y en menor medida artículos de uso personal ${ }^{31}$. Una vez más el fuerte San José representa la excepción, ya

Corpus, Vol 5, No 1 | 2015 
que en toda la documentación histórica correspondiente a la década analizada no se registraron listas de esta naturaleza ni una esfera formal e institucionalizada de agasajo e intercambio ${ }^{32}$. Ello podría ser resultado del carácter subalterno del fuerte San José y haber afectado del algún modo las relaciones con los indígenas, teniendo en cuenta la importancia de la materialidad en la estructuración de las relaciones interétnicas.

No podemos desconocer que a pesar de las conocidas consecuencias negativas de estos procesos a largo plazo - la creciente dependencia con respecto a los productos de origen europeo y el impacto sobre los sistemas socioculturales autóctonos-, las comunidades indígenas supieron aprovechar las ventajas que les representaba en términos políticos, económicos y sociales la negociación con la fracción hispano-criolla. De acuerdo a Quijada:

[...] las dádivas o raciones aportadas periódicamente por la sociedad hispano-criolla a los indígenas [...] se convirtieron en un engranaje importante del sistema sociopolítico de estos últimos, no sólo porque aportaban productos que ellos consideraban crecientemente necesarios - tanto material como simbólicamente (bienes de prestigio) - sino sobre todo porque constituían una parte significativa de las redes de reciprocidad que mantenían las formas de sociabilidad y autoridad indígenas, tanto intra como intertribales (Quijada, 2002, p.118-119).

Por otro lado, como ya mencioné, en el caso de los establecimientos patagónicos la necesidad de mantener una interacción estable y pacífica con las poblaciones locales fue un factor decisivo en la continuidad de los mismos, debido al escaso apoyo que recibían desde la administración virreinal. En este sentido la memoria escrita por Francisco Viedma expone con claridad esta política, aunque curiosamente deja afuera al fuerte San José:

Los indios salvajes nos sostuvieron y fomentaron en aquel puerto [se refiere a San Julián], socorriendo a los infelices pobladores con la carne de guanaco, sin cuyo auxilio hubieran perecido, y en el Río Negro con las liebres, caballos y mucho ganado vacuno [...] (Viedma, 1969 [1784]).

Por lo tanto, las políticas pacíficas y de negociación con las poblaciones en el contexto particular de Patagonia a fines del siglo XVIII fueron un factor que seguramente contribuyó de gran manera a disminuir la incertidumbre y los riesgos inherentes al carácter fundacional de los establecimientos coloniales, sobre todo en sus fases iniciales. Ahora bien, teniendo en cuenta estas condiciones y antecedentes me pregunto cómo se estructuraron en la práctica las relaciones interétnicas en el contexto del fuerte San José.

\section{Las relaciones interétnicas en península Valdés}

En este apartado me abocaré a describir y discutir, en función de las condiciones, los antecedentes y los interrogantes cómo fueron las relaciones interétnicas en el escenario de península Valdés a fines del siglo XVIII. En este escenario inicial dominado por poblaciones indígenas, es válido interrogarse si las mismas aprovecharon de manera estratégica la vulnerabilidad del fuerte en función de sus propios intereses o bien se relacionaron como lo hicieron con los otros dos asentamientos. En base a ello, también habría que preguntarse ¿cómo se inserta la fundación del fuerte San José y el Puesto de la Fuente en el control que las poblaciones indígenas tenían sobre la península y sus recursos? Al respecto, no debemos olvidar la presencia de dos grandes salinas, que probablemente fueran aprovechadas desde tiempos inmemoriales por los 
grupos indígenas patagónicos para el autoabastecimiento y el intercambio. La instalación del Puesto de la Fuente en los márgenes de la Salina Grande ¿pudo generar un conflicto de intereses por la explotación de la misma? Dada la situación de precariedad que habría signado al fuerte a lo largo de su existencia ¿tenía recursos para ofrecer en el marco de las prácticas de negociación e intercambio con las poblaciones indígenas?

Para desarrollar este abordaje me centraré en los primeros 10 años de funcionamiento de los establecimientos sobre la base del análisis de fuentes primarias tanto éditas como inéditas. Con respecto de estas últimas, el corpus más importante procede del Archivo General de la Nación -en adelante AGN-, del cual se analizaron para este trabajo 19 legajos correspondientes a la Sala IX para el período considerado: 16-2-9, 16-3-2 al 16-3-12, 16-4-2 al 16-4-7, Sala X, legajo 16-5-10, Sala VII, Legajo 193 y Sala XIII, Legajos 34-10-5, 26-6-6, 31-1-5.33 Asimismo, se estudiaron documentos inéditos procedentes de las los repositorios del Archivo General de Indias -en adelante AGI- (Sevilla), el Archivo Histórico de Madrid -en adelante AH-y de la Fundação Biblioteca Nacional de Río de Janeiro, Brasil -en adelante FBN.

El conocimiento generado a lo largo de estos años en torno a la Nueva Colonia y fuerte de Floridablanca (Senatore, 2002, 2005, 2007; Senatore, et al. 2007 y 2008; Bianchi Villelli, 2007a y b, 2009; Marschoff, 2007 y 2010; Buscaglia, 2008, 2011a y b, 2012; Buscaglia y Nuviala, 2007; Buscaglia et al., 2008, Nuviala, 2008; Bosoni, 2010; entre otros) como sobre el fuerte Nuestra Señora del Carmen (Entraigas, 1960; Gorla, 1983 y 1984; Nacuzzi, 1999, 2002 y 2005; Irurtia, 2002; Luiz, 2006a y b; Davies, 2009; Enrique, 2011, 2012; Casanueva, 2011, 2013; Casanueva y Murgo, 2009, entre otros), ha permitido obtener una imagen muy completa del funcionamiento y las características de estos dos asentamientos a lo largo del tiempo. Al abordar el corpus documental disponible para el fuerte San José y el Puesto de la Fuente uno de los primeros aspectos que llamaron mi atención fue la ausencia de referencias sobre el contacto con indígenas durante los primeros años del asentamiento, a diferencia del fuerte Nuestra Señora del Carmen y Floridablanca. Al menos en la documentación relevada en el AGN, el registro para las relaciones interétnicas recién comienza en el año 1787 extendiéndose hasta 1789, siendo prácticamente nulo para los años anteriores, cuyas razones y significado trataré de desentrañar a continuación.

\subsection{Península Valdés: el desierto imaginado}

46 A diferencia por ejemplo del fuerte Nuestra Señora del Carmen y Floridablanca, que se establecieron en territorios y en momentos con presencia efectiva de poblaciones indígenas, entablando el contacto con las mismas desde el inicio del proceso poblador, en el caso del fuerte San José el panorama étnico inicial en la península y territorios aledaños nunca fue objeto de tratamiento en las fuentes históricas directas. No será hasta 1786/1787 que las fuentes primarias analizadas darán cuenta, y de forma casi abrupta, de relaciones hostiles entre indígenas y la población española en la península. Sin embargo, es Antonio Viedma, quien en su Descripción de la costa meridional...en base a la información suministrada por los tehuelches de San Julián, aporta el único dato respecto al conocimiento y dominio indígena del área del golfo San José, como se transcribe a continuación:

El golfo san José está al sur del cabo de Matas [...]. Dijeron los indios que el golfo entra al $\mathrm{O}$. hasta las inmediaciones de la Cordillera, y que allí desaguan algunos 
manantiales de ella. Que por aquella parte es intransitable también a la otra banda: que allí se halla mucha leña de espinillo marchando del N. al S. por donde dichos indios tienen abiertas veredas para transitar, de modo que, si se separan de ellas quedan perdidos. La costa $\mathrm{S}$. del golfo, dicen, es más estéril que la del N.; y en cuanto a caza y pesca hay las mismas que los anteriores. Los caciques que dominan este suelo son dos hermanos llamados, el uno Chaiguas y el otro Enis (Viedma, $1972 b$ [1783], p.940-941). fases exploratorias de la empresa de poblamiento como al arribo de los contingentes pobladores. De hecho, en el caso de Floridablanca, la elección del lugar de emplazamiento del poblado dependió de la información suministrada por los indígenas locales (Viedma, 1972a [1783]). Cabe señalar que tanto en el caso del área seleccionada para la instalación del fuerte San José como en el área de los manantiales, De la Piedra no da cuenta de indicadores materiales - ni antiguos ni recientes- relacionados con indígenas -i.e. restos de artefactos líticos, fogones, huesos, huellas, etc.-, a pesar de su conocimiento respecto de los mismos. Esta misma observación se repite en el diario de Villarino (1779) en el que refiere: "Hicimos algunas mudanzas de lugar, para establecernos con más ventajas junto al puerto. En éste no encontramos vestigios de gente ni de indios [...]" ${ }^{37}$. Incluso Villarino para 1782 en un informe elevado a Francisco Viedma expone: "allí pueden tenerse 2.000 y más de cabeza de ganado vacuno, se pueden tener caballos y ganado lanar sin recelo que los indios los roben" (Villarino, 1969 [1782], p.227). Como veremos más adelante, el tiempo probaría cuán equivocado estaba el piloto.

51 En notable contraste con estas imágenes, los antecedentes de investigaciones arqueológicas en la península dan cuenta de una ocupación de cazadores-recolectores en la misma al menos desde el Holoceno medio hasta momentos históricos (7420+90 - 
250+60 años 14C AP), observándose un aumento de las ocupaciones del interior en detrimento de la costa, por lo que resulta indudable la importancia de este territorio para las poblaciones indígenas a lo largo del tiempo (Belardi, 2005; Gómez Otero, 2007; Gómez Otero et al., 1999, entre otros). Incluso luego de la destrucción del fuerte San José, las poblaciones indígenas continuaron ocupando la península, aprovechando el ganado cimarrón que comenzó a reproducirse naturalmente. Claro ejemplo de ello son las referencias que datan de 1821 respecto al abastecimiento que el cacique Ojo Lindo realizara al fuerte del Carmen con vacunos procedentes de península Valdés (Bustos, 1993) y la contabilización de decenas de miles de vacunos que hicieran Ambrosio Crámer y Henry Libanus Jones por aquellos años (Dumrauf, 1991). Al respecto, se destacan también las restricciones que la cacica María impusiera a Luis Vernet -socio de Jones- para capturar vacunos, cuando se encontraron por primera vez en la península en 1823 (Dumrauf, 1991; Videla y Del Castillo Bernal, 2003). Sin embargo, hasta el momento no se han registrado evidencias materiales irrefutables de contacto en los contextos investigados arqueológicamente, aunque sí indicios que podrían estar en ese camino o al menos apuntar a una superposición en el uso del espacio por parte de poblaciones indígenas y europeas, particularmente en el área donde se encuentra situado el Puesto de la Fuente, estratégica en términos de disponibilidad de agua dulce, sal y pasturas, entre otras cosas (Alberti y Buscaglia, s/f) (Figura 3).

Figura 3. a) Vista de la Salina Grande, b) restos de una estructura de piedra identificada en el Puesto de la Fuente y c) artefactos líticos y pipa de cerámica de origen europeo recuperados durante las investigaciones arqueológicas (Fotos: Marcia Bianchi Villelli y Silvana Buscaglia).

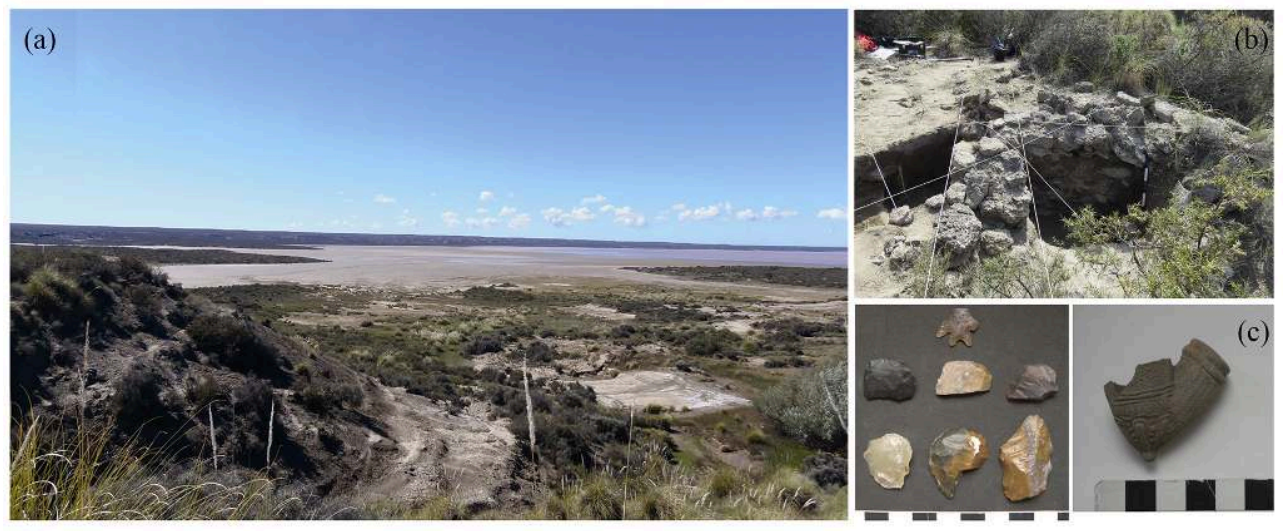

Sobre esta base resulta necesario indagar -tanto desde el punto de vista histórico como del arqueológico- en las causas de la ausencia de un contacto inicial entre la expedición fundadora y los indígenas, máxime si tenemos en cuenta los antecedentes para Floridablanca y Nuestra Señora del Carmen, en los cuales el trato y la información suministrada por los segundos fue crucial para garantizar el éxito inicial de la empresa de poblamiento. De manera similar a Floridablanca, los inicios del proceso poblador en el caso del fuerte San José no estuvieron libres de dificultades. ¿Por qué entonces no se menciona el contacto con indígenas? ¿Se trata de una omisión deliberada o efectivamente aquellos eludieron el contacto con los pobladores del fuerte? Si este fuera el caso ¿qué los habría motivado a evitar un territorio rico en recursos y ocupado ancestralmente? ¿La presencia colonial en península Valdés alteró de alguna manera la dinámica de las poblaciones indígenas en la era postcontacto? De los tres establecimientos, el fuerte San José fue el de menor importancia ¿es posible que a los ojos de los indígenas tuviera un menor atractivo en términos materiales, políticos y sociales? Por otro lado, sus existencias ganaderas no alcanzaron un número 
significativo hasta mediados-fines de la década de $1780^{38}$ ni se verificó tampoco el comercio con los indígenas a propósito de este recurso, como sí fue el caso del fuerte Nuestra Señora del Carmen y Floridablanca (Gorla, 1983; Nacuzzi, 2005; Buscaglia, 2012, entre otros). Por el momento, el único acontecimiento significativo que pudo haber introducido cambios en el circuito de movilidad e intercambio, particularmente de grupos de tehuelches meridionales, fue el abandono de Floridablanca en 1784, convirtiendo al fuerte San José en un nuevo foco de atracción para las poblaciones indígenas patagónicas. Como desarrollaré a continuación, las referencias respecto a la presencia indígena en el área del fuerte comienzan a partir de 1786/1787, teniendo como protagonistas principales a los grupos que frecuentaban la Patagonia meridional, y en particular el área de San Julián.

\subsection{Las poblaciones indígenas entran en escena}

Hasta aquí hemos visto, sobre la base de la confrontación de distintas fuentes históricas, un llamativo silencio respecto al contacto con poblaciones indígenas en península Valdés durante al menos 8 años -entre 1779 y 1786/1787-, hasta que una serie de episodios conflictivos irrumpen en la escena para romper con este sospechoso cuadro de ausencia de interacciones, al menos desde el plano discursivo.

Sobre la base de la información disponible me pregunto por qué a partir de este momento tienen lugar los primeros encuentros y quiénes habrían participado de los mismos, a los efectos de comprender la forma en que se estructuraron las relaciones interétnicas en la península.

En 1783, el teniente de infantería don José de Salazar -quien descubriera el camino por tierra entre San José y el Carmen para la conducción de ganado-, señala en su diario el peligro potencial que representaban los indígenas para el fuerte, proponiéndose la fortificación del istmo que une a la península con el continente, tal como lo presento a continuación:

Para el menor costo de la Real Hacienda en la subsistencia de aquel Puerto, seguridad de sus ganados, y resguardo de sus habitadores, me parecía que en la lengua de tierra o angostura que forma la Península de este Puerto y el del Sur, se construyera con estacas, por ahora un fortín provisional [...].

Tomada esta angostura se consiguieran tres cosas: primera, impedir que los Indios [...] puedan entrar a aquella península, con tan reducida guarnición [...], segunda: que todo el ganado que se lleve o arríe está segurísimo de perderse, y no necesita de peones que lo guarden y pastoreen. Tercera: que los presidiarios que se destinen para los trabajos de la sal y demás que ocurran no pueden desertarse aunque estén en toda libertad..$^{39}$

Si bien dicha información constituye una referencia temprana sobre los recelos ante los indígenas, aún no contamos con datos adicionales para determinar si este temor era producto de expectativas o un conocimiento certero por parte de los expedicionarios. Entre 1784 y 1785, un segundo hecho a destacar, aparte del abandono de Floridablanca, fueron las cruentas acciones que De la Piedra llevó contra los tehuelches septentrionales que frecuentaban las inmediaciones de los ríos Negro y Colorado, con el fallido desenlace que tuvo la expedición a la Sierra de la Ventana y un ofrecimiento de paz a principios de 1786 por parte de importantes caciques como Negro ${ }^{40}$, Calpisqui, Toro, entre otros (Gorla, 1983, p. 137). Si bien estos tratados de paz tenían poca efectividad en la práctica, sería interesante evaluar cómo ello incidió en las relaciones 
entre el fuerte Nuestra Señora del Carmen, el fuerte San José y los tehuelches meridionales, ya que por ejemplo el cacique Julián Camelo se había manifestado abiertamente como enemigo del cacique Negro o Chanel (Viedma 1972a [1783], p. 907) ${ }^{41}$. Asimismo, si bien entre 1784 y 1789 se observa un incremento de los vacunos y equinos en fuerte San José, apenas superaron el medio centenar de cabezas en cada caso, un número extremadamente escaso en comparación al fuerte Nuestra Señora del Carmen (Gorla, 1983).

En la documentación existente en el Archivo General de la Nación la primera mención detectada hasta el momento sobre la presencia efectiva de indígenas en el contexto de los establecimientos españoles en península Valdés data del 3 de enero de 1787, donde el teniente de dragones don José Martínez habría comunicado que, como consecuencia de la presencia de indígenas en el área, el peón Manuel Sanz y el soldado del Regimiento de Burgos, Alonso Parra, habrían desaparecido aunque sin poder determinar el modo en que los dos individuos fueron capturados, ya que no fueron vistos por nadie ${ }^{42}$. Sin embargo, el comandante señala en otro oficio que cuando salieron a buscar a los hombres en algún paraje cercano a la entrada de la península: “... lo único que encontramos fue el lugar donde habían estado hasta cuarenta hombres según el rastro de los caballos y estos no traían toldos pues no se encontró señal de ellos". Asimismo, da cuenta del temor que dejó en el destacamento esta acción llevada a cabo por los indígenas, al mencionar que por seguridad se construyó un cerco alrededor del cerro donde estaban emplazados y un corral en la "Estancia" para el ganado, lo que podría estar indicando que previo al hecho los animales pastasen libremente, sin que ninguna amenaza se cerniera sobre los mismos ${ }^{43}$.

Debido al temor suscitado por este episodio, el comandante de San José solicitó auxilios al fuerte de Río Negro, los cuales fueron despachados desde allí el 5 de julio de 1787 y arribaron a San José once días más tarde. Al respecto, en un oficio del mes de noviembre de 1787 se reporta en relación al capitán y piloto de la embarcación don Pedro Casariego que:

El catorce de agosto a las cuatro de la tarde partió para el predicho Río Negro habiéndole detenido todo este tiempo el Gobernador de aquel fuerte a fin de que le auxiliase con el socorro posible, y la Gente de su tripulación por estar alterados los Indios [...]. ${ }^{44}$

En septiembre ${ }^{45}$ de ese mismo año el bergantín regresa a San José con pertrechos y municiones. Es importante mencionar respecto a este incidente que en el análisis de los oficios intercambiados entre los distintos funcionarios - fuerte San José, fuerte del Carmen y Buenos Aires- se pone de relieve el no haberlo comunicado de la forma correspondiente, recriminándosele al comandante de San José la omisión de importantes detalles así como el escaso control sobre los pobladores ${ }^{46}$, poniendo en evidencia la falta de autoridad efectiva en la práctica.

Durante los meses de junio y julio de ese mismo año vuelven a repetirse los conflictos entre indígenas y españoles. En un oficio del 7 de agosto de 1787 se refiere, para el mes de junio de dicho año, el avistaje de jinetes indígenas a la distancia en las inmediaciones del fuerte San José, lo que alertó al nuevo comandante Pedro Burniño a enviar órdenes inmediatas para asegurar el Puesto de la Fuente y el ganado allí existente. Como resultado de este encuentro, murió un soldado y supuestamente el cacique Julián Camelo -líder de los toldos de San Julián-, como se relata en uno de los principales pasajes de un extenso documento que parcialmente citamos a continuación: 
A eso de las cuatro de la misma tarde llegó el Capataz de Don Francisco Medina y el Presidiario Gaspar Gómez con dos caballos ensillados de diestro, estos me avisaron que a corta distancia de la Laguna del Monte, distante de este Puesto dos leguas y media, a poco tiempo de haberse separado de ellos dicho Mansilla les salieron cinco Indios que según ellos comprendieron eran de los de San Julián y entre estos venía el Cacique Julián Camelo [...]. Pasó el Cacique Julián a persuadir al Capataz y al Presidiario [...] a fin de que fuesen a sus toldos, que ellos eran amigos preguntándoles, que en donde estaban las Mulas y Caballos, procurándoles engañar [...]. Al cabo de cerca de una hora de pelea, tuvo la proporción de asegurarle un tiro de pistola a quemarropa al Cacique Julián, que lo dejó muerto, lo que visto por los cuatro Indios restantes disparó uno de ellos, y se infiere pudo ir a avisar a los demás, que según las señas daba el mismo Cacique estaban acampados en una laguna distante de la fuente como dos leguas, ya amedrentados los citados Indios que quedaban, viendo el valor del Capataz huyeron, y entonces tomaron los dos caballos de diestro en los que venía el soldado, y el del Cacique muerto, uno y otro con todo recado, procurando ganar este Puerto, como lo hicieron, sin haber tenido más desgracia los dos, que haber recibido una leve contusión de un bolazo en la mano derecha el Presidiario Gaspar, y haber oído al mismo tiempo de retirarse gritar al soldado por lo que infieren lo estarían chuceando. ${ }^{47}$ (El destacado me pertenece).

Sin embargo, pueden plantearse dudas respecto de si el indígena asesinado fue el cacique Julián Camelo, ya que el comandante del fuerte San José en su relato sobre los hechos menciona que cuando le trajeron la cabeza del cacique:

[...] por lo desfigurada que estaba no pude conocer si era la del Cacique Julián, pero creo que será la de él por haberle visto igual recado de montar, y por el modo de accionar de que me informó el que lo mató. ${ }^{48}$

Por otro lado, en una declaración tomada en septiembre de 1787 a un indígena ${ }^{49}$, presuntamente perteneciente a la gente de Julián, respecto al robo de ganado y asesinatos de un poblador y soldado en el fuerte Nuestra Señora del Carmen, se refiere:

Preguntado qué Indios fueron los que invadieron por dos veces el Puerto de San José y en qué número.

Responde: Que la primera vez concurrió el cacique Camaen con seis indios y se llevaron cautivo al soldado Alonso Parra, a quien dio una puñalada al tiempo de prenderlo uno de los indios y que al Peón lo mataron: Que la segunda vez concurrieron los caciques Cogeuma y Guari, con muchos Indios cuyo número ignora y que mataron al soldado Toribio y un indio que mataron últimamente en el San José se llama Guetechunque, hermano del Cacique Guari.

Preguntado: Cómo adquirió las noticias que refiere.

Responde: Que por habérselo oído a los mismos Indios que asistieron y no sabe más. 50

63 De acuerdo a las noticias suministradas en este documento, dos fueron las "invasiones" que realizaron los indígenas en 1787. Asimismo, el testimonio del indígena cautivo corrobora la captura y muerte respectivamente del soldado y el peón del fuerte San José. En cuanto a los caciques implicados, estos serían parientes y/o aliados del cacique Julián Camelo. De hecho Camaen, por un error fonético o de transcripción, podría ser el cacique Carmen, señalado como aliado de Julián en el diario de Viedma ([1783] 1972a, p. 907). Sobre la base de esta declaración podría haber sido otro hombre con el que confundieron al cacique Julián -Guetechunque, referido como hermano del cacique Guari-, lo que se pondrá en evidencia nuevamente en el año 1788, como desarrollaré más adelante. 

regresaron al Puesto de la Fuente para llevarse ganado, como se refiere a continuación: faena de Don Francisco Medina a todo riesgo con un parte del Cabo en que me avisaba, que entre tres y cuatro de la tarde se agolparon como doscientos Indios al tiempo que venía la Caballada y Boyada al corral, y se llevaron la mayor parte del ganado a excepción de unos 20 animales, que a estos tuvieron tiempo de encerrarles a uno de los corrales, y los otros no pudieron librarlos porque los Enemigos no dieron tiempo de poner las tranqueras al otro corral, y con el fuego de los Pedreros y fusilería le mataron el caballo a uno de los Indios [...]..$^{51}$

Ya sea que la captura de animales fuera la causa principal de su presencia o bien una venganza por la muerte de uno de los indígenas, es importante mencionar que estos episodios ponen de manifiesto la vulnerabilidad de los dos asentamientos en península Valdés frente a una fuerza indígena claramente superior desde el punto de vista del conocimiento y los hombres. Sin embargo, el grado de violencia implicado en las acciones por parte de ambos grupos así como la toma de cautivos podría estar indicando la intervención de otras causales, que trasciendan la sustracción de ganado, que como señalé era bastante escaso.

\subsection{El principio del fin: la absurda captura y muerte del cacique Julián Camelo}

Las referencias respecto de las relaciones interétnicas para 1788 comienzan con un oficio referido a la captura de dos mujeres indígenas presuntamente pertenecientes a las tolderías del cacique Julián Camelo ${ }^{52}$ para intercambiarlas por el soldado Alfonso Parra, tomado cautivo en San José el año anterior. En el documento no se precisa cómo ni dónde son capturadas las mujeres, y además, en otro oficio posterior se siembra confusión respecto a las tolderías a las cuales pertenecían las mujeres, ya que en esta ocasión se refiere que los caciques Chulilaquini ${ }^{53}$ y Bueno incumplen el trato de traer al soldado Alonso Parra para intercambiarlo por las chinas ${ }^{54}$. De ello se infieren al menos dos explicaciones posibles: 1) que los caciques fueran confundidos, o 2) que los cautivos fueran robados, intercambiados o vendidos entre los indígenas.

Para el mes de mayo de 1788 vuelven a encontrarse referencias sobre la interacción con indígenas en el contexto del fuerte San José y el Puesto de la Fuente. Una vez más los protagonistas de las mismas son el cacique Julián y su gente, cuya mención introduce ambigüedad al relato sobre su supuesta muerte en junio de 1787. En este nuevo documento se consigna que:

El 27 de mayo último se apareció en este puerto el indio Cacique Julián acompañado de dos chinas y dos indios diciendo que su venida se dirigía a pasear, y saber, qué capitán era yo, si era bueno, para después traer sus toldos, que se componen (según él) de muchas chinas que hacen muchos cueros para presentarme, añadiendo que también venía a avisarme, como el Cacique Sapa quería robarme las Vacas cuya artificiosa prevención me puso en cuidado y más cuando supe que en mi ausencia había preguntado que por donde teníamos las vacas. Concluido esto habiéndole obsequiado con pan y vino que tomó, pidió que le dieran de comer, mandé darle carne y porotos, pero no los quiso admitir, manifestando mucho disgusto de que le diese aquella carne salada, añadiendo que yo era Capitán malo, pobre, que no le daba Aguardiente ni Yerba cuyas demostraciones y el informe que en el acto me dio José Revalluda, Peón de Don Francisco Medina, de que un caballo saino negro, orejas rajadas y marcado con una cruz, que trajo dicho Julián entre los suyos, era uno de 
17 que llevaron los Indios del citado Julián pertenecientes a dicho Don Francisco Medina, y a más de 26 caballos y 18 bueyes del Rey que mataron a chuza, y otros oreyanos del marinero pescador y de un soldado, todo lo cual testifica el mencionado Peón con el capataz Thomás Mansilla, y con el Peón Amado Fervor que dice, existen ambos en este Río Negro.

Y pareciéndome no debía despreciar este informe, que todo el conviene con la pública notoriedad y especialmente con el dictamen del Sargento Mayor de Dragones, Don José Ignacio de la Quintana, a quién oí decir que este Indio con su gente, es el que robó una porción del ganado en este Río Negro después de haberle colmado de beneficios, me resolví a arrestarle y el 22 le puse a bordo del Barco la Piedad con proporcionada custodia, de donde estimulándole la conciencia, me mandó decir, que él nunca había venido a hacer daño, que quien vino anteriormente a robar fue un hermano suyo, el que es muy malo, cuya prevenida excusa acredita que él fue el que robó en éste y ese Puerto de Río Negro.

En fin, en su custodia va encargado el subteniente de Granaderos Don Bernardo Durán, prevenido de que no debe omitir precaución alguna para su seguridad, hasta entregarlo ahí con más los dos indios y las dos chinas que le acompañan, que llevan consigo todos los aperos de montar y sólo quedan en mi poder siete caballos y tres mulas pertenecientes a ellos. ${ }^{55}$

El documento sirve para ilustrar el carácter variable de las interacciones y la intención de los indígenas de instalar sus toldos en cercanía a los asentamientos españoles, e incluso la alusión a las "chinas" - más allá de la manufactura de cueros pintados o quillangos para su intercambio- es importante en cuanto a su significación en el contexto de un asentamiento militar aislado y con un componente demográfico predominantemente masculino. Además, un dato no menor es la mención a la matanza de caballos y bueyes pertenecientes a los españoles por parte de los indígenas. Esta acción tiende un manto de duda sobre si el objetivo de los malones era únicamente la sustracción de hacienda para su aprovechamiento o comercialización. Por último, el comandante de San José no deja pasar la oportunidad de apropiarse de los caballos y las mulas de los indígenas, en beneficio del fuerte.

Durante el traslado en barco hacia el fuerte Nuestra Señora del Carmen, el cacique Julián y otro indígena se fugaron, con el fatal desenlace del asesinato del primero y la captura del segundo a manos de los españoles, en un excesivo acto de represalia, tal como se presenta a continuación:

Declaración de Sebastián de la Calle, natural de Villa de Pedroche, reino de Córdoba, soldado de la $2^{\circ}$ Compañía del 2 o Batallón del Regimiento de Infantería de Burgos.

Preguntado: Si sabe a qué hora cómo y dónde hicieron fuga dos Indios de los que estaban a cargo del subteniente de Granaderos Don Bernardo Durán.

Responde: Que entre 2 luces estando rezando el rosario a la voz de los Indios al agua volviendo la cabeza hacia la proa el que declara vio caer un Indio al agua por la Jarcia que está al lado de la Cámara de los Marineros, a cuyo tiempo acudió la tropa a las Armas, y los marineros al bote y el que declara junto con el soldado Santiago Carrelero llevando un fusil cargado, pero sin cebo como lo experimentó cuando llegó el caso de hacerles fuego a uno de los dos Indios que se escaparon y salió a tierra, porque al $1^{\circ}$ de los Indios que alcanzamos con el bote se le mató a puñaladas por no habérsele podido coger de otro modo, y ya muerto éste en el agua que claramente se reconoció por su barba, estatura y gordura que era el cacique Julián, seguimos al otro que ya estaba en tierra y habiéndonos desembarcado seguimos las huellas por la arena hasta llegar a un montecito de dos cuadras de la orilla del agua y del pie de una mata de dicho monte salió el indio de improviso con un cuchillo y embistiendo con el mencionado Carralero se echó el que declara el fusil a la cara y habiéndole errado fuego dos veces se quedó cortado por no tener otra arma entre todos más que el mencionado fusil en cuyo tiempo se volvió a 
esconder el Indio y habiéndonos reunido volvimos en su busca a solicitud y no pudiendo dar con él nos metimos en el bote y nos vinimos a bordo a dar parte al Comandante de los acaecido [...]. ${ }^{56}$ (El destacado me pertenece). propone como solución el proyecto de excavar una zanja a lo largo del tramo más angosto del istmo - como lo sugiriera Salazar en 1783 y tal como Alsina lo pusiera en práctica unos cien años más tarde al oeste de la provincia de Buenos Aires-, con el fin de impedir el paso de los indígenas y mudar el fuerte allí, por presentar mejores condiciones que su ubicación actual:

Sin embargo, que ud estará informado que de resulta de las hostilidades que han hecho anteriormente los Indios en este Puesto se han tomado las providencias capaces de evitarlas en lo sucesivo; no puedo menos que hacer presente a ud lo imperiosas que son y serán cuántas se tomen, mientras no mude este Puesto de situación en los términos que explicaré a ud más adelante.

No ignora ud que toda la tropa que en el día tenemos es la mayor parte bisoña en el manejo del caballo, luego es consiguiente que siempre que venga un cuantioso número de indios, y a los que estén de pastoreo con los bueyes y caballos, les den un intempestivo asalto, les arrebataran todos los animales y los dejaran burlados, esto es, haciéndoles favor de la vida, porque si hacen el fuego montados, es caso negado que tenga efecto, si echan pie a tierra y se unen en formación no dudo que se defiendan, pero con esto no se consigue el fin que es guardar dichos animales y cuando esto no sea, quien podrá evitar que en el medio del camino, cuando las carretas vengan con agua, les cargue un golpe de indios con caballada por delante tomando el barlovento sofocándoles con el polvo, consigan desordenarlos y derrotarlos enteramente. Nadie dificultará de que esto pueda suceder y por último, quien tenga un mediano conocimiento convendrá en que unos bueyes que comen muy poco y que todas las noches duermen encerrados, puedan tirar una carreta cargada seis leguas de camino, cosa es inconcebible pero a la verdad es realidad, agregándose a esta desdicha la de estar dichos bueyes lo mismo que esqueletos. Con que es consiguiente [...] que con la imposibilidad que queda demostrada, queda este destacamento en estado poco menos que de perecer, porque el traer agua de la fuente a pie es imposible, así por no haber vasijas aparentes como por la distancia, y sin ella no hay pan. Llevar harina a la fuente aunque poca, pudiera ser, pero esto sería infructuoso por no haber horno; con que concluimos en que sería preciso que cada uno tomase un poco de carne y menestra y marchara a la fuente para comerla, sin quedar otro recurso.

Llegando este caso y que viniera algún Barco, sería preciso que estuviese dos meses para descargar aguardando la oportunidad de la marea para atracar a las peñas y poner la carga en tierra en donde permanecería a la inclemencia por falta de carretillas en qué conducir a los almacenes, aunque para decir verdad, ponerla en estos o dejar en el campo, es todo uno, de tal suerte que con mil cueros dudo que haya suficiente para cubrir almacenes, panadería y habitaciones, por todo necesita renovarse por su total destrucción y sería doloroso, se hiciesen tan grandes gastos en un puesto que por las razones dichas, es imposible el conservar, a menos que se sitúe en la angostura o boca de esta península, en donde según opinión de Don Antonio Rodríguez, Piloto del Barco de la Piedad, no hay más distancia que media legua de mar a mar [...].

Sentado para que esto sea aprobado se necesitan los auxilios siguientes:

[...]

Sesenta presidiarios con treinta picos, treinta asadas y treinta palas a fin de que según el terreno usen de la herramienta que convenga para hacer una zanja que absolutamente imposibilite a los indios el paso de una a otra costa del mar [...]. ${ }^{57}$

71 Como puede apreciarse, este documento pone de manifiesto la situación de extrema vulnerabilidad en la que se encontraban tanto el Puesto de la Fuente como el fuerte San 
José, tanto desde el punto de vista defensivo como de las condiciones de vida que debían afrontar, situación que no habría pasado desapercibida a los indígenas. Sin embargo, este proyecto no contó con los auxilios necesarios para poder ser puesto finalmente en práctica.

72 A partir de 1789 se observa una notable disminución de referencias respecto de las relaciones interétnicas y actos de hostilidad emprendidos por indígenas. Tan solo se registró una sola mención, pero a hechos ocurridos en el año anterior, respecto de los cuales no se hallaron por el momento los documentos correspondientes:

Excelentísimo Sr: Hecho cargo del oficio de 16 de abril último que en contestación me dirige vuestra excelencia de hallarse enterado de las providencias que tomó el Comandante del fuerte San José las cuales no dieron lugar a las invasiones que intentaron los indios las veces que se les presentaron en el invierno pasado [...] ${ }^{58}$

Para entender las razones de este impasse habría que evaluar en una perspectiva diacrónica si el mismo se fundamenta en una reorganización de las distintas parcialidades indígenas, debido a la muerte de algunos de sus caciques más importantes. Respecto a esta posibilidad, es sugestivo que para noviembre de ese mismo año, en una carta dirigida al comandante del fuerte Nuestra Señora del Carmen, el Virrey Loreto ordena aumentar la vigilancia en las fronteras de dicho establecimiento y sus puertos, teniendo en cuenta las noticias sobre la "reunión de los de Tierra Adentro en el Volcán". ${ }^{9}$

\section{Discusión y conclusiones}

74 La información hasta aquí presentada ha puesto en evidencia, por un lado, la vulnerabilidad del fuerte San José y el Puesto de la Fuente como resultado del abandono y la falta de auxilios por parte de las autoridades virreinales. Esta situación no habría pasado desapercibida a las poblaciones indígenas, quienes pudieron haber aprovechado esta condición. A diferencia del fuerte Nuestra Señora del Carmen y la Colonia de Floridablanca, las relaciones interétnicas en el contexto del fuerte San José fueron discontinuas en el tiempo - tan solo se han registrado con seguridad tres episodios- $y$ predominantemente hostiles, señalándose como principales protagonistas a tehuelches procedentes de la Patagonia meridional, como el cacique Julián y sus aliados.

75 El carácter hostil de las interacciones nos lleva a la segunda cuestión: el alcance de las políticas borbónicas en relación al contacto. En el caso de estudio aquí presentado, a diferencia de los otros dos establecimientos mencionados, no se observa desde el plano discursivo ningún intento de atracción o negociación con las poblaciones indígenas, incluso cuando una relación pacífica con las mismas podría haber contribuido no solo a una mejora en las condiciones de vida de la población del fuerte y el Puesto de la Fuente durante sus primeros años, sino a incrementar sus existencias ganaderas, como se observó en el caso del fuerte Nuestra Señora del Carmen (Gorla, 1983; Bustos, 1993). Es importante destacar que no se asume esta imagen como dada, sino que es necesario evaluarla a la luz de la evidencia arqueológica para identificar correspondencias y contradicciones entre ambas líneas de evidencia. En este sentido y por el momento las investigaciones realizadas en el Puesto de la Fuente indican que se trató de un área con cierta importancia para las poblaciones locales en momentos tardíos, aunque la cultura material hasta ahora recuperada es insuficiente para avalar o descartar el contacto entre ambas poblaciones (Alberti y Buscaglia, s/f). 
76 He señalado que entre 1787 y 1788 se produjeron con seguridad tres incursiones de los indígenas en la península. La primera de ellas tuvo lugar en enero de 1787, aparentemente dirigida por el cacique Camaen y tuvo como resultado la captura de un soldado y el asesinato de un peón en algún paraje cercano al fuerte San José. La segunda incursión habría sido comandada por los caciques Cogeuma y Guari, en la que fueron asesinados, en un paraje distante del fuerte unas dos leguas y media, un soldado y un indígena llamado Guentechunque, señalado como hermano del cacique Guari y confundido con el cacique Julián Camelo por los españoles. Como consecuencia posiblemente de estas acciones, el mismo día por la noche, los indígenas robaron cerca de medio centenar de caballos y mataron 18 bueyes. Creemos que la matanza de bueyes es significativa en términos de lo que representaba para la población de San José: el único medio para transportar el agua desde el Puesto de la Fuente al fuerte en la costa, y garantizar de este modo la subsistencia de los habitantes de este puesto. Esta abre el interrogante sobre si no existieron otros motivos -que trascendían la obtención de ganado- que llevaran a los indígenas a hostilizar los establecimientos españoles en península Valdés. Finalmente, el tercer episodio tiene lugar en mayo de 1788 cuando un reaparecido cacique Julián se presenta en el fuerte con motivos de intercambio. Sin embargo, como consecuencia de la identificación de caballos robados el año anterior, tanto en San José como en el Carmen, es apresado y asesinado durante su traslado al Río Negro.

77 Si los consideramos a lo largo de la década, se trata de episodios aislados, cuya repercusión sin embargo no fue menor dada la pérdida de vidas humanas, de líderes de importancia - como el cacique Julián Camelo entre los tehuelches- y de animales esenciales para el desarrollo de la vida diaria del asentamiento colonial. Además, es importante señalar que, exceptuando al cacique Julián, para el resto de los caciques e indígenas no hemos encontrado referencias que los sitúen en las áreas de influencia del fuerte Nuestra Señora del Carmen y Floridablanca.

Respecto de las causas de estas acciones, aún no podemos establecer a ciencia cierta cuáles fueron. Sin embargo, pensamos que deben ser interpretadas no solo en función de la sustracción de ganado, sino también en relación a los cambios producidos tanto en las sociedades indígenas como en los establecimientos coloniales en Patagonia durante la década de 1780.

En primer lugar, si las acciones contra el fuerte San José fueron encabezadas por el cacique Julián y aliados, como parece desprenderse de la documentación histórica, pensamos que el abandono de Floridablanca de alguna manera repercutió en la reestructuración de las prácticas de estos grupos en función de la reconfiguración de las redes de obtención de recursos y bienes así como de las esferas de poder. Como ya mencionamos, la relación del grupo de este cacique con la colonia fue pacífica, cotidiana y prácticamente continua durante los cuatro años que funcionó la misma, hasta el punto de que redujeron sus visitas al fuerte Nuestra Señora del Carmen (Buscaglia, 2011a, 2012). Es importante mencionar que mientras funcionó Floridablanca, no se registraron en las fuentes históricas consultadas contactos entre los tehuelches de San Julián y el fuerte San José (Luiz, 2006a; Nacuzzi, 2005, Davies, 2009; Buscaglia, s/f). La fundación de la colonia en su territorio permitía acceder a los indígenas de forma directa a los productos de origen europeo y criollo, muchos de ellos altamente valorados para reforzar el prestigio y el poder tanto dentro como fuera del grupo, mediante mecanismos de apropiación, redistribución e intercambio. Al respecto 
es elocuente la observación que en 1783 realiza el piloto Basilio Villarino: "En este río [Río Negro, la aclaración es mía] se hallaron estos indios con los tehuelches de San Julián, con los cuales hicieron mucho comercio, porque venían muy ricos con las alhajas que les habían regalado los cristianos de aquel establecimiento" (Villarino en De Angelis, 1972, p. 1123). Por lo tanto, la desaparición de Floridablanca habría significado para los tehuelches que frecuentaban San Julián la pérdida no solo de una fuente de abastecimiento directo sino también de aliados entre los españoles ${ }^{60}$.

En segundo lugar, si la experiencia con Floridablanca certifica el desarrollo de relaciones de convivencia amistosas y de ayuda mutua entre este grupo de indígenas y la población hispano-criolla, entonces es necesario preguntarse por qué no se siguió este camino en el fuerte San José, a pesar de su condición de mayor vulnerabilidad y la ambivalencia que caracterizó la estructuración de las relaciones interétnicas. En este sentido, como se ha acreditado para el caso del fuerte Nuestra Señora del Carmen (Gorla, 1983; Nacuzzi, 2005; Luiz, 2006a, entre otros), el robo de ganado y la violencia fueron tolerados y formaban parte de la vida cotidiana de estos asentamientos, ya que garantizar la asistencia por parte de los indígenas era más importante. Un aspecto a considerar, que a mi criterio juega un rol fundamental en la forma en que se pusieron en práctica las políticas borbónicas de contacto y la manera en que se estructuran diferencialmente las relaciones interétnicas en los tres asentamientos, se relaciona con los funcionarios que estuvieron al frente de las colonias y los fuertes. En este sentido la política de los hermanos Francisco y Antonio Viedma así como la continuidad de sus funciones en el tiempo, difiere sustancialmente de los militares que sucedieron en el mando del fuerte San José. La condición castrense de los mismos, su posible falta de experiencia en el trato con indígenas y un sistema anual de relevos, probablemente desalentaron un contacto sostenido en el tiempo, sumando a ello los temores producto de la comandancia de asentamientos aislados y escasos de hombres y recursos.

81 En tercer lugar, y en relación con los aspectos mencionados, el fuerte San José, a diferencia del fuerte Nuestra Señora del Carmen y Floridablanca, se encontraba en una inferioridad de condiciones materiales para sostener una política de agasajo e intercambio - tanto desde el punto de vista de las esferas formales como informalescon las poblaciones indígenas de manera de poder negociar con las mismas ayuda y alianzas. En este sentido, queda pendiente analizar por qué no se abasteció al fuerte con suministros para interactuar con las poblaciones locales. Una hipótesis podría ser la subestimación de las mismas respecto a la situación de aislamiento del fuerte San José durante sus primeros años, como ya he descripto. La escasez de recursos materiales incluso ganado- pudo haber afectado negativamente la suerte del fuerte respecto de su relación con las poblaciones locales.

82 En cuarto lugar, y no por ello menos importante, la creación sobre todo del Puesto de la Fuente sumado al recelo de los hispano-criollos, pudo haber significado una restricción al acceso a recursos de importancia estratégica en un paradero reutilizado en el tiempo $\mathrm{y}$ en el marco de sus circuitos anuales de movilidad por las poblaciones indígenas, particularmente en momentos tardíos. De hecho, dentro de la península, el área de la Salina Grande donde se encuentra emplazado dicho puesto, concentra recursos esenciales para la vida de estas poblaciones: manantiales permanentes de agua dulce, sal, animales de presa y pasturas (Belardi, 2005; Gómez Otero, 2007; Gómez Otero et al., 1999; Alberti y Buscaglia, s/f). 
83 la efectividad del poder colonial sobre las poblaciones indígenas. La realidad testimoniada por el aislamiento, el desconocimiento, la escasez de fuerzas militares, el desabastecimiento, en suma, la inestabilidad que caracterizó a las colonias, sobre todo en sus fases iniciales, hace inevitable pensar en el manejo estratégico de las poblaciones locales de sus relaciones con estos pequeños y marginales núcleos poblacionales. Desde esta perspectiva, no es posible dejar de reconocer el poder y la agencia de las poblaciones indígenas en relación a la estructuración de las relaciones interétnicas y, por ende, su intervención tanto en los niveles más altos de la política y la economía de la sociedad colonial como en la esfera de la vida cotidiana de estos poblados.

finalizar, considero que el presente trabajo ha dejado más interrogantes que certezas respecto a la estructuración de las relaciones interétnicas en el contexto del fuerte San José. La respuesta a dichos interrogantes requiere avanzar progresivamente en el análisis a nivel diacrónico y comparativo en la historia y la materialidad de los asentamientos, así como de las distintas parcialidades indígenas que interactuaron con los establecimientos patagónicos. Una interpretación de los contextos particulares, en perspectiva holística y comparativa, requiere asimismo desentrañar los significados emergentes a partir de la integración y confrontación de múltiples líneas de evidencia, así como de las representaciones relativas a la realidad cotidiana de las interacciones entre indígenas y colonizadores en la Patagonia del siglo XVIII. Comprender las relaciones interétnicas en sus múltiples expresiones y dimensiones en el contexto de San José forma parte del intento de recuperar su complejidad y descorrer el velo de estigmatización que tanto tiempo ha pesado sobre la representación del contacto cultural en este escenario particular.

\section{BIBLIOGRAPHY}

Alberti, J. y Buscaglia, S. (s/f). Caracterización de los conjuntos líticos artefactuales del sitio Puesto de la Fuente (estancia Los Manantiales, península Valdés, provincia de Chubut). Intersecciones en Antropología (en prensa).

Arias, F. (2008). Las reducciones jesuíticas de la frontera bonaerense y su vínculo con la red de establecimientos en tierras 'coloniales', 1740-1753. Boletín Geográfico, Año XXIX, 32. En prensa.

Bagaloni, V. N. (2006). Contacto interétnico fronterizo. Un caso arqueológico de mestizaje cultural. En P. P. Funari y F. R. Brittez (Comps.), Arqueología histórica en América Latina: Temas y discusiones recientes (pp. 23-48). Mar del Plata: Ediciones Suárez.

Barba Ruiz, L. (2000). Acontecimientos históricos de península Valdés. Rawson: Comisión ProMonumentos a las gestas y primeras colonizaciones españolas del Chubut.

Barba Ruiz, L. (2009). Quiénes colonizaron la Patagonia en el siglo XVIII. Trelew: Biblioteca Popular “Agustín Álvarez” (2 Edición).

Belardi, J. B. (2005). Paisajes arqueológicos: Un estudio comparativo de diferentes ambientes patagónicos. Oxford: BAR International Series 1390.

Corpus, Vol 5, No 1 | 2015 
Bianchi Villelli, M. (2007a). Organizar la diferencia. Prácticas de consumo en Floridablanca. Serie Proyecto Floridablanca. Buenos Aires: Editorial Teseo.

Bianchi Villelli, M. (2007b). ¿Espacios de cambio social? Los espacios no proyectados por la Corona en la población española de Floridablanca (San Julián, Siglo XVIII). En F. Morello, A. Prieto, M. Martinic y C. Bahamonde (Eds.), Arqueología de Fuego-Patagonia. Levantando piedras, desenterrando huesos...y develando arcanos (pp. 787-799). Punta Arenas: Ediciones CEQUA.

Bianchi Villelli, M. (2009). Cambio social y prácticas cotidianas en el orden colonial. Arqueología histórica en Floridablanca (San Julián, Siglo XVIII). Oxford: BAR International Series 039.

Bianchi Villelli, M. (2011). La "historia" del fuerte San José (península Valdés, 1779-1810). Primeros abordajes. En M. Ramos, A. Tapia, F. Bognanni, M. Fernández, V. Helfer, C. Landa, M. Lanza, E. Montanari, E. Néspolo y V. Pineau (Eds.), Temas y problemas de la Arqueología Histórica (Tomo I, pp. 55-68). Luján: Programa de Arqueología Histórica y Estudios Pluridisciplinarios (PROARHEP). Departamento de Ciencias Sociales. Universidad Nacional de Luján.

Bianchi Villelli, M. (2012, noviembre). Historia y colonialismo: la Patagonia "hiperreal" de fines del siglo XVIII. Cuadernos de trabajo CLACSO 16, disponible en http://www.clacso.org.ar/ area_academica/2b5_libro_detalle.php?idioma=\&id_libro=749\&pageNum_rs_libros=6.

Bianchi Villelli, M. (2014, enero-junio). La materialidad como artilugio historiográfico. Espacios, mapas y asentamientos coloniales en la costa patagónica (siglo XVIII). Tábula Rasa, 20, 285-303.

Bianchi Villelli, M., Buscaglia, S. y Sancci, B. (2013). Una genealogía de los planos históricos de los asentamientos coloniales del fuerte San José, península Valdés (Siglo XVIII). Corpus. Archivos virtuales de alteridad americana, 3 (1), 1-14.

Bosoni, C. (2010). Entre lo dicho y lo hecho: Prácticas productivas en la colonia española de Floridablanca (Patagonia, siglo XVIII). Tesis de Licenciatura inédita, Facultad de Filosofía y Letras-UBA.

Briones, C. y Carrasco M. (2000). Pacta sunt servanda. Capitulaciones, convenios y tratados con indígenas en Pampa y Patagonia (Argentina 1742-1878). Buenos Aires: International Work Group for Indigenous Affairs y Vinciguerra Testimonios.

Buscaglia, S. (2008). Los marinos malditos. Identidad, poder y materialidad (San Julián, Pcia. de Santa Cruz, Siglo XVIII). Vestigios. Revista Latinoamericana de Arqueología Histórica, 2 (1), 35-62.

Buscaglia, S. (2010). Agencia indígena y colonialismo. El caso de los establecimientos patagónicos (siglos XVIII-XIX). Proyecto de Carrera de Investigador, CONICET. Ms.

Buscaglia, S. (2011a). Fronteras permeables en Floridablanca: Agencia indígena y vida cotidiana (Patagonia, Siglo XVIII). En M. Ramos, A. Tapia, F. Bognanni, M. Fernández, V. Helfer, C. Landa, M. Lanza, E. Montanari, E. Néspolo y V. Pineau (Eds.), Temas y problemas de la arqueología histórica (Tomo I, pp. 179-196). Luján: Programa de Arqueología Histórica y Estudios Pluridisciplinarios (PROARHEP). Departamento de Ciencias Sociales. Universidad Nacional de Luján.

Buscaglia, S. (2011b). La representación de las relaciones interétnicas en el discurso de Antonio Viedma (Patagonia Meridional, Siglo XVIII). Magallania, 39 (2), 15-35.

Buscaglia, S. (2011c). Contacto y colonialismo. Aportes para una discusión crítica en arqueología histórica. En Anuario de Arqueología. Actas del Primer Simposio Magistral de Arqueología Colonial, 3 (3), 57-76. Santa Fe: FHyA de la Universidad Nacional de Rosario,

Buscaglia, S. (2012). Poder y dinámica interétnica en la colonia española de Floridablanca. Una perspectiva histórica y arqueológica (Patagonia, Argentina, Siglo XVIII). Alemania: Editorial Académica Española (publicación de la Tesis Doctoral, 2009). 
Buscaglia, S. (2013). Diálogo entre la arqueología histórica y los estudios poscoloniales. PasadoPorvenir, 7, 49-65.

Buscaglia, S. (s/f). Relaciones interétnicas en el fuerte San José (Patagonia, Siglo XVIII). Una aproximación comparativa. Revista Española de Antropología Americana. (Enviado en octubre 2013, en evaluación).

Buscaglia, S. y Bianchi Villelli, M. (s/f). From Colonial Representation to Materiality: Spanish Settlements on Península Valdés (Patagonian Coast, 1779-1810). Historical Archaeology (enviado en marzo 2014).

Buscaglia, S. y Bianchi Villelli, M. (2012). Arqueología histórica en el fuerte San José. Perspectivas arqueológicas y discusión crítica de fuentes. En A. F. Sangrando, R. Barberena, A. Gil, G. Neme, M. Giardina, L. Luna, C. Otaola, S. Paulides, L. Salgán y A. Tivoli (Comps.), Tendencias teóricometodológicas y casos de estudio en la arqueología de la Patagonia (pp. 147-156). Buenos Aires: Sociedad Argentina de Antropología.

Buscaglia, S. y Nuviala, V. (2007). Pocos espejitos de colores. La construcción material del contacto en Floridablanca (San Julián, siglo XVIII). En F. Morello, A. Prieto, M. Martinic y C. Bahamonde (Eds.) Arqueología de Fuego-Patagonia. Levantando piedras, desenterrando huesos... y develando arcanos (pp. 813-824). Punta Arenas: Ediciones CEQUA.

Buscaglia, S., Bianchi Villelli, M., Starópoli, L., Bosoni, C., Carelli S. y Alberti J. (2012). Arqueología histórica en península Valdés. Primeros abordajes históricos y arqueológicos al fuerte San José (1779-1810). Revista de Arqueología Histórica Argentina y Latinoamericana, (6), 47-79.

Buscaglia, S., Senatore, M. X., Lascano, M. E., Bongiovanni V., De la Vega M. y Osella, A. (2008). To Project an order. Interdisciplinary Perspectives on Spatial Construction in the Spanish Colony of Floridablanca (Patagonia, 18th Century). Historical Archaeology, 42 (4), 1-20.

Bustos, J. A. (1993). Indios y blancos, sal y ganado más allá de la frontera. Patagones 1820-1830. Anuario del IEHS, 8, 2745.

Casanueva, M. L. (2011). Colonos maragatos en la frontera austral del Virreinato del Río de la Plata (cuevas en Nuestra Señora del Carmen de Patagones). Revista Tierras de León, 128-129, 123-153.

Casanueva, M. L. (2013). Inmigrantes tempranos: Maragatos en la Patagonia argentina. Las cuevas del fuerte Nuestra Señora de El Carmen. Revista Española de Antropología Americana, 43 (1), 111-132.

Casanueva, M. L. y Murgo A. (2009). Primeros pobladores españoles en el fuerte-poblado de El Carmen, Patagonia argentina (finales del siglo XVIII). Revista de Arqueología Histórica Argentina y Latinoamericana, 3, 19-46.

Claraz, J. (1988 [1865-66]). Diario de viaje de exploración al Chubut, 1865-1866. Buenos Aires: Marymar.

D’ Orbigny, A. (1999 [1835-1847]). Viaje por la América Meridional. Tomo II. Buenos Aires: Emecé.

Darwin, Ch. (2003 [1839]). Diario del viaje de un naturalista alrededor del mundo. Buenos Aires: Elefante Blanco.

Davies, G. (2009). Rescates o compras indígenas en Carmen de Patagones (1795-1836): un fenómeno particular de mestizaje. En J. Farberman y S. Ratto (Coords.), Historias mestizas en el Tucumán colonial y las pampas (siglos XVII-XIX) (pp. 115-1439. Buenos Aires: Biblos.

De Angelis, P. (1969). Extracto resumido de lo que ha ocurrido en la expedición del descubrimiento de la Bahía Sin Fondo, en la costa patagónica. En Colección Pedro De Angelis (Tomo IV, pp. 166-171). Buenos Aires: Plus Ultra. 
De Paula, A. (1984). Fortificaciones en el litoral marítimo patagónico durante el dominio español. En II Congreso de Historia Argentina y Regional 8, Tomo II, (pp. 227-241). Buenos Aires: Academia Nacional de la Historia.

Destéfani, L. H. (1984). La colonización patagónica. En Historia marítima argentina, (Tomo IV, pp. 179-217). Buenos Aires: PN Editores.

Di Paolo, L. D. (2001). Social skins. Orthodoxies and practices of dressing in the early colonial Mississippi Valley. Journal of Social Archaeology, 1 (2), 172-189.

Dumrauf, C. (1991). Un precursor en la colonización del Chubut. Documentos sobre la actuación de Enrique Libanus Jones en el Chubut. En Textos Ameghinianos. Chubut: Biblioteca de la Fundación Ameghino.

Dumrauf, C. (1992). Historia de Chubut. Buenos Aires: Plus Ultra.

Enrique, L. A. (2011). Disputas de sentido en la construcción del paisaje del norte de la Patagonia a fines del siglo XVIII. En Actas del X Congreso de Antropología Social. La Antropología interpelada: nuevas configuraciones políticas-culturales en América Latina. Buenos Aires. publicación digital, Facultad de Filosofía y Letras, UBA.

Enrique, L. A. (2012). La percepción de los expedicionarios virreinales sobre el manejo indígena de territorios y recursos del norte de la Patagonia a fines del siglo XVIII. Revista Española de Antropología Americana, 42 (2), 449-466.

Entraigas, R. A. (1960). El fuerte del Río Negro. Buenos Aires: Librería Don Bosco.

Entraigas, R. A. (1968). Sangre en península de Valdés. Martirio del Padre B. Poggio. Cuadernos de Historia del Chubut, 4, 9-32.

Fontana, L. J. (1999 [1886]). Viaje de exploración en la Patagonia austral. Buenos Aires: Confluencia.

Fontana, L. J. (1873). Despoblación de San José en la costa patagónica. Revista del Río de la Plata, (7), 330-336.

Foucault, M. (2001 [1976]). Vigilar y castigar. Nacimiento de la prisión. D. F., México: Ed. Siglo XXI.

Gavirati, M. (2012). El contacto entre galeses, pampas y tehuelches: la conformación de un modelo de convivencia pacífica en la Patagonia central (1865-1885). Tesis Doctoral inédita, Facultad de Ciencias Humanas, Universidad del Centro de la Provincia de Buenos Aires.

Giddens, A. (1995). La constitución de la sociedad. Bases para la teoría de la estructuración. Buenos Aires: Amorrortu Editores.

Gómez Otero J., Belardi, J., Súnico, C. y Taylor, R. (1999). Arqueología de cazadores-recolectores en península Valdés (costa central de Patagonia): primeros resultados. En Soplando el viento... Actas de las Terceras Jornadas de Arqueología de la Patagonia (pp. 393-41). Neuquén: Universidad Nacional del Comahue.

Gómez Otero, J. (2007). Dieta, uso del espacio y evolución en poblaciones cazadoras-recolectoras de la costa centro-septentrional de Patagonia durante el Holoceno medio y tardío. Tesis doctoral inédita. Facultad de Filosofía y Letras, Universidad de Buenos Aires.

Gorla, C. M. (1983). Origen y evolución de la ganadería patagónica (1779-1810). Buenos Aires: Fundación para la Educación, la Ciencia y la Cultura.

Gorla, C. M. (1984). Los establecimientos españoles en la Patagonia. Estudio institucional. Sevilla: Escuela de Estudios Hispanoamericanos de Sevilla, Consejo Superior de Investigaciones Científicas. 
Hajduk, A., Albornoz, A. M., Lezcano, M.J. y Montero, G. (2013). De Chiloé al Nahuel Huapi. Nuevas evidencias materiales del accionar jesuítico en el gran lago (siglos XVII y XVIII). En M. A. Nicoletti y Paula Núñez (Comps.) Araucanía - Norpatagonia: la territorialidad en debate. Perspectivas ambientales, culturales, sociales, políticas y económicas. Publicación del II Taller Binacional Argentino Chileno Araucanía-Norpatagonia (pp. 243-279). Bariloche: Instituto de Investigaciones en Diversidad Cultural y Procesos de Cambio y Universidad Nacional de Río Negro, San Carlos de Bariloche.

Hall, M. (1999) Subaltern voices? Finding the spaces between things and words. En P. P. A. Funari, M. Hall y S. Jones (Eds.), Historical Archaeology: Back from the Edge (pp. 193-203). Londres: Routledge.

Irurtia, M. P. (2002). La visión de los indios respecto de los "cristianos" y "huincas" en el norte de la Patagonia, siglos XVIII y XIX. En L. R. Nacuzzi (Comp.), Funcionarios, diplomáticos, guerreros.

Miradas hacia el otro en las fronteras de Pampa y Patagonia (Siglos XVIII y XIX), (247-285). Buenos Aires: Sociedad Argentina de Antropología.

Irurtia, M. P. (2007). Intercambio, novedad y estrategias: las misiones jesuíticas del sur desde la perspectiva indígena. Avá, 11, 135-167.

Lanöel, A., Barba Ruiz, L., Zapatero, J. M. y M Gutiérrez Neri, A. (1974). Recopilación histórica sobre el fuerte San José. Chubut: Comisión Pro-monumentos a las Gestas y Primeras Colonizaciones Españolas del Chubut, Dirección de Turismo.

Liebmann, M. J. (2008). Introduction: The intersections of Archaeology and postcolonial studies. En M. J. Liebmann y U. Z. Rivzi (Eds.) Archaeology and the Postcolonial Critique (pp. 1-20). Lanham, New York, Toronto, Plymouth: Altamira Press.

Lightfoot, K. G., Martínez, A.y Schiff, A. M. (1998). Daily practice and material culture in pluralistic social settings: An archaeological study of culture change and persistence from Fort Ross, California. American Antiquity, 63 (2), 199-222.

Lozano, P. P. (1972 [1745]). Diario de un viaje a la costa de la Mar Magallánica en 1745 desde Buenos Aires hasta el Estrecho de Magallanes formado sobre las observaciones de los Padres Cardiel y Quiroga por el Padre Pedro Lozano. En Colección Pedro De Angelis (Tomo III, pp. 587-633). Buenos Aires: Plus Ultra.

Luiz, M. T. (2006a). Relaciones fronterizas en Patagonia. La convivencia hispano-indígena a fines del período colonial. Ushuaia: Asociación Hanis, Universidad Nacional de la Patagonia San Juan Bosco.

Luiz, M. T. (2006b). La construcción de un espacio fronterizo: cambios en las relaciones interétnicas y permanencias en las representaciones del otro y lo otro. Patagonia a fines del período colonial. En S. Bandieri, G. Blanco y G. Varela (Dir.) Hecho en Patagonia. La historia en perspectiva regional (pp. 125-1419. Neuquén: Educo.

Lynch, J. (1992). The institutional framework of colonial Spanish America. Journal of Latin American Studies, 24, 69-81.

Lyndon, J. (2006). Pacific encounters, or beyond the islands of history. En M. Hall y S. W. Silliman (Eds.) Historical Archaeology (pp. 312). UK, USA y Australia: Blackwell Publishing.

Mallon, F. (1994). The promise and dilemma of subaltern studies: Perspectives from Latin American History. The American Historical Review, 9 (5), 1491-1515.

Mandrini, R. (1987). Desarrollo de una sociedad indígena pastoril en el área interserrana bonaerense. Anuario del IEHS, 2, 71-97.

Mandrini, R. (1993). Guerra y paz en la frontera bonaerense durante el siglo XVIII. Ciencia Hoy, 22, 23-35. 
Mandrini, R. (1997). Las fronteras y la sociedad indígena en el ámbito pampeano. Anuario del IEHS, 12, 23-34.

Marschoff, M. (2007). Gato por liebre. Prácticas alimenticias en Floridablanca. Serie Proyecto Floridablanca. Buenos Aires: Editorial Teseo.

Marschoff, M. (2010). Experimentación social e identidad. Arqueología e historia en Floridablanca (Siglo XVIII). Tesis doctoral inédita, Facultad de Filosofía y Letras, Universidad de Buenos Aires.

Martínez de Gorla, D. M. (2004). La Patagonia en una nueva proyección. Caza-pesca marítima y agricultura en el siglo XVIII. En separata de las XIX Jornadas de Historia Económica, Buenos Aires.

Mayo, C. (2000). Vivir en la frontera. La casa, la dieta, la pulpería, la escuela (1770-1870). Buenos Aires: Editorial Biblos.

Musters, G. C. (1997 [1871]). Vida entre los Patagones. Un año de excursiones por tierras no frecuentadas desde el Estrecho de Magallanes hasta el Río Negro. Buenos Aires: Elefante Blanco.

Nacuzzi, L. R. (1999). Los caciques del Río Negro a fines del siglo XVIII. En Etnohistoria: artículos, disponible en http://etnohistoria.naya.org.ar/htm/20_articulo.htm (acceso el 24/4/2014).

Nacuzzi, L. R. (2002). Francisco de Viedma, un "Cacique Blanco" en tierra de indios. En L. R. Nacuzzi (Comp.), Funcionarios, diplomáticos, guerreros. Miradas hacia el otro en las fronteras de Pampa y Patagonia (siglos XVIII y XIX) (pp. 25-64). Buenos Aires: Sociedad Argentina de Antropología.

Nacuzzi, L. R. (2005). Identidades impuestas. Tehuelches, aucas y pampas en el norte de la Patagonia. Buenos Aires: Sociedad Argentina de Antropología ( $2^{\circ}$ edición).

Néspolo, E. (2005). Las misiones jesuíticas bonaerenses del siglo XVIII, ¿una estrategia políticoeconómica Indígena? Revista Tefros 5 (1), Invierno 2007. http://www.unrc.edu.ar/ publicar/tefros/revista/v5n1i07/paquetes/nespolo.pdf (acceso 15/2/2014).

Nicoletti, M. E. (2004). Los jesuitas en el Nahuel Huapi: aproximaciones a una breve misión en la Patagonia (1669-1717). Memoria Americana. Cuadernos de Etnohistoria, 12, 97-130.

Nuviala, M. V. (2008). Materializando identidades en Floridablanca. Los artefactos de uso personal en la comunicación no verbal de las identidades (Patagonia, siglo XVIII). Tesis de Licenciatura inédita, Facultad de Filosofía y Letras, Universidad de Buenos Aires.

Operé, F. (2001). Historias de la frontera: el cautiverio en la América hispánica. Buenos Aires: Fondo de Cultura Económica.

Palermo, M. A. (1989). Indígenas en el mercado colonial. Ciencia Hoy, 1 (4), 22-26.

Pedrotta, V. (2013). Reducción jesuítica Nuestra Señora de la Purísima Concepción de los Indios Pampas (Castelli, provincia de Buenos Aires): crónica de una década de reclamos e inacción. Revista del Museo de la Plata, 13 (87), 493-508.

Pedrotta, V. y Bagaloni, V. (2006). Looking at interethnic relations in the southern border through glass remains: The Nineteenth-Century Pampa region, Argentina. International Journal of Historical Archaeology, 9 (3), 177-193.

Quijada, M. (2002). Repensando la frontera sur argentina: concepto, contenido, continuidades y discontinuidades de una realidad espacial y étnica (siglos XVIII-XIX). Revista de Indias, 62 (224), 103-142.

Sarrailh, J. (1992). La España Ilustrada de la segunda mitad del Siglo XVIII. Madrid: Fondo de Cultura Económica. 
Scaramelli, F. (2005). Material Culture, Colonialism and Identity in the Middle Orinoco, Venezuela. Tesis de doctorado, Departamento de Antropología, Universidad de Chicago. Chicago, Illinois. Ms.

Scott, J. (1990). Domination and Arts of Resistence. Hidden Transcripts. New Haven y Londres: Yale University Press.

Senatore, M. X (2005). Enlightened discourse, representations and social practices in the Spanish settlement of Floridablanca (Patagonia, 18th century). En P. P Funari, A. Zarankin y E. Stobel (Eds.), Global Archaeological Theory, Contextual Voices and Contemporary Thoughts (pp. 559-669). New York: Springer.

Senatore, M. X. (2007). Arqueología e historia en la colonia española de Floridablanca. Patagonia, Siglo XVIII. Serie Arqueología Histórica. Proyecto Floridablanca. Buenos Aires: Editorial Teseo.

Senatore, M. X. (2002). Discursos iluministas e ordem social: representações materiais na colônia de Floridablanca em San Julián (Patagônia, século XVIII). En A. Zarankin y M. X Senatore, Arqueologia da Sociedade Moderna na América do Sul. Cultura Material, Discursos e Prácticas (pp. 87-106). Buenos Aires: Ediciones del Tridente.

Senatore, M. X., Marschoff, M., Bianchi Villelli, M., Buscaglia, S., Nuviala, V., Bosoni C. y Starópoli, L. (2008). Una arqueología de las prácticas cotidianas en Floridablanca (Patagonia, Siglo XVIII). En Arqueología en el Extremo Sur de Sudamérica (pp. 81-117). Buenos Aires: Dunken.

Senatore, M. X., Buscaglia, S., Bianchi Villelli, M., Marschoff, M., Palombo, P., Nuviala, V., Milanés, C. y Bosoni, C. (2007). Imágenes de Floridablanca. La construcción material y narrativa de la colonia española de San Julián (Siglo XVIII). En F. Morello, A. Prieto, M. Martinic y C. Bahamonde (Eds.), Arqueología de Fuego-Patagonia. Levantando piedras, desenterrando huesos... y develando arcanos (pp. 801-812). Punta Arenas: Ediciones CEQUA.

Silliman, S. (2001). Agency, practical politics and the Achaeology of cultural contact. Journal of Social Archaeology, 1 (2), 190-209.

Silliman, S. (2006). Struggling with labor, working with identities. En M. Hall y S. Silliman (eds.), Historical Archaeology (pp. 147-166). Malden y Londres: Blackwell Publishing.

Silliman, S. (2010). Indigenous traces in colonial spaces: Archaeologies of ambiguity, origin and practice. Journal of Social Archaeology, 10 (1), 28-58.

Spivak, G. C. (1994). Can the subaltern speak? En P. Williams y L. Chrisman (Eds.) Colonial and Postcolonial Theory (p. 66-111). Columbia University Press, New York.

Urbina Burgos, R. (1990). Las misiones franciscanas de Chiloé a fines del siglo XVIII: 1771-1800.

Valparaíso: Lártole Editorial, Serie Monografías Históricas, Instituto de Historia, Universidad Católica de Valparaíso.

Vértiz, J. J. (1938 [1778]). Oficio del Virrey Vértiz, Buenos Aires, 3 de noviembre de 1778. Revista de la Biblioteca Nacional, Tomo II, 1, 351-363.

Videla, L. E. M. y Del Castillo Bernal, M. F. (2003). Reinas y guerreros. Sobre jefaturas indígenas en la Patagonia meridional. En IX Jornadas Escuela/Departamentos de Historia. Córdoba, edición digital.

Viedma, A. (1972a [1783]). Diario de Viedma. En Colección Pedro De Angelis (Tomo VIII, vol. B, pp. 845-936). Buenos Aires: Plus Ultra.

Viedma, A. (1972b [1783]). Descripción de la costa meridional del sur llamada vulgarmente patagónica. Relación de sus terrenos, producciones, brutos, aves y peces; indios que la habitan, su religión, costumbres, vestido y trato desde el Puerto de Santa Elena en 44 grados hasta el de la Virgen en 52 y boca del estrecho de Magallanes. Refiérese cuanto en dicha costa y tierra caminó y 
reconoció por sí. D. Antonio de Viedma, en el tiempo de su destino en aquellos establecimientos, y su particular comisión en el de San Julián, con las demás noticias que pudo adquirir de los indios. En Colección Pedro De Angelis (Tomo VIII, vol. B, pp. 937-966). Buenos Aires: Plus Ultra.

Viedma, F. (1969 [1784]). Memoria dirigida al Señor Marqués de Loreto. En Colección Pedro De Angelis (Tomo III, pp. 643-684) Buenos Aires: Plus Ultra.

Villarino, B. (1969 [1782]). Informe de D. Basilio Villarino, Piloto de la Real Armada, sobre los puertos de la costa Patagónica. En Colección Pedro De Angelis (Tomo IV, pp. 220-229). Buenos Aires: Plus Ultra.

Vives Ferradiz Sánchez, J. (2006). Tras los pasos de una arqueología postcolonial. En Negociando Encuentros: situaciones coloniales e intercambios en la costa oriental de la Península Ibérica (Siglos VIII-VI AC) (Cap. I, pp. 27-48). Barcelona: Bellaterrra.

Voss, B. L. (2008). The Archaeology of Ethnogenesis. Race and sexuality in Colonial San Francisco. California: University California Press.

Weber, D. J. (1998). Borbones y bárbaros. Centro y periferia en la reformulación de la política de España hacia los indígenas no sometidos. Anuario del IEHS, 13, 147-171.

Zusman, P. (1999). ¿Terra Australis-"Res Nullius"? El avance de la frontera colonial hispánica en la patagonia (1778-1784). Scripta Nova Revista Electrónica de Geografía y Ciencias Sociales [Online], 45 (34). Disponible en: http://www.ub.es/geocrit/sn-45-34.htm.

\section{NOTES}

1. Co-dirigido por la Dra. Bianchi Villelli y quien suscribe.

2. Exceptuando las investigaciones de Carlos M. Gorla, quien en su estudio sobre el origen y desarrollo sobre la ganadería patagónica (1983) discute el rol de los indígenas en esta actividad, integrando información histórica respecto al fuerte San José.

3. La persistencia de estas ideas en el imaginario popular se ha reflejado y materializado, por ejemplo, en las placas conmemorativas colocadas en la réplica de la capilla de San José, situada frente a la Isla de los Pájaros. A modo de ejemplo, en una de ellas puede leerse: "Las sociedades españolas de la Provincia rinden homenaje a los primeros mártires del Chubut. A los sobrevivientes de la primera colonización Juan Coca, Francisco Rodríguez, Juan Centeno, Juan Albornoz, Casimiro Novacos, con nuestro reconocimiento a los muertos en la lucha [...]". Es importante destacar que la réplica de la capilla fue construida sobre la base de una interpretación errónea de los planos asignados al fuerte San José, corroborándose que en realidad los mismos correspondían al fuerte San José y Ciudadela de Montevideo (Bianchi Villelli et al., 2013).

4. Esta perspectiva parte de una discusión crítica del colonialismo, las aproximaciones binarias y los esencialismos para dar cuenta de las relaciones interétnicas. Así, se busca poner de relieve el rol activo de los diversos actores sociales que fueron subalternizados por el poder y el discurso colonial, de manera de entender el contacto entre los diferentes agentes en función de su carácter multidireccional y cuestionando de este modo la impermeabilidad de las estructuras coloniales (Ligthfoot et al., 1998; Di Paolo, 2001; Silliman, 2001, 2006 y 2010; Scaramelli, 2005; Lyndon, 2006; Vives Ferradiz Sánchez, 2006; Voss, 2008; Liebmann, 2008; Buscaglia, 2011c, 2013, entre otros).

5. Es importante aclarar que las relaciones interétnicas en el contexto del fuerte San José no fueron problematizadas en su real complejidad desde la historia, mientras que desde lo arqueológico, constituyen una problemática que recién ha comenzado a desarrollarse en función 
del progresivo avance de las investigaciones y las particularidades de la evidencia material recuperada (ver por ejemplo Alberti y Buscaglia, s/f).

6. En el marco de mi tesis doctoral defendida en abril de 2009 y publicada en 2012, me aboqué al análisis de la estructuración de las relaciones de poder en el contexto de la colonia de Floridablanca, poniendo el foco en la relación entre el proyecto social implícito (Senatore, 2007) y las prácticas cotidianas de aquellos actores que fueron subalternizados por el poder colonial. Uno de estos grupos fue el de los marinos, perteneciente al contingente poblador, pero fuertemente estigmatizado por el poder colonial. El segundo grupo corresponde a la parcialidad de tehuelches que se relacionó con la Colonia durante sus cuatro años de funcionamiento. En este contexto, el énfasis de la investigación estuvo puesto en la agencia y el impacto diferencial de estos dos grupos de actores en función de su potencial para alterar el orden colonial y/o generar alternativas al mismo.

7. Fundação Biblioteca Nacional, MS-508 (40) Doc.1164 "Diario de la Expedición de Don José de Salazar al Puerto de San José, 1783" y Archivo Histórico de Madrid, sección Estado, legajo 2316 "Diario de la expedición del mando del Comisario Superintendente Don Juan de la Piedra que con 4 embarcaciones armadas en guerra y 114 hombres de Tropa de Tierra con sus respectivos Oficiales, sale del Puerto de Montevideo el 15 de diciembre de 1778 en busca del nombrado Bahía Sin Fondo en la costa Patagónica debiendo después de dejar allí hecho un establecimiento seguir a formar otro al Puerto de San Julián".

8. Si bien la documentación histórica es elusiva en lo que refiere a la descripción arquitectónica del mismo, no obstante se han encontrado referencias aisladas que dan cuenta de la construcción de ranchos precarios, corrales y posiblemente un galpón para el acopio de sal, aunque sin precisar su localización. Las investigaciones arqueológicas realizadas en el mes de marzo de 2013 han permitido identificar al menos tres estructuras de piedra en la estancia Los Manantiales, una de ellas parcialmente en pie aunque con evidencias de haber sido saqueada a lo largo del tiempo. Por el momento, dada la escasez de la evidencia arqueológica registrada no ha podido asignarse con seguridad esta estructura a la ocupación española de fines del siglo XVIII, aunque se han identificado restos arqueológicos compatibles con la misma en sus alrededores (Buscaglia y Bianchi Villelli, 2013).

9. Aspecto que también será destacado por Fontana en su reconocimiento de la actual provincia de Chubut ([1886] 1999).

10. Fundação Biblioteca Nacional, MS-508 (40) Doc.1164 "Diario de la Expedición de Don José de Salazar al Puerto de San José, 1783".

11. En 1782 el piloto Basilio Villarino describe la importancia estratégica del puerto San José "por la facilidad y limpieza de este y su entrada, por ser su fondo de buena tenazón, y por la proporcionada altura o situación en que se halla, me parece muy propio para que sirva de puerto de arribada a las embarcaciones que navegan a la mar del sur". En dicho informe el piloto destaca el peligro de dejar despoblado este puerto, debido a las ventajas estratégicas para el ingreso de embarcaciones enemigas que podrían alcanzar desde allí el Río Negro como otras áreas colonizadas por los españoles y aliarse con las naciones indígenas que frecuentaban la costa patagónica (Villarino, [1782] 1969: 228).

12. Los comandantes del fuerte San José entre 1779 y 1789 fueron: Juan de la Piedra, Francisco Viedma, Antonio Viedma (1779), Pedro García (ca. 1779-1782), Juan Antonio Martínez (1782), Juan José Gómez (1783), José de Salazar (1784), Salvador José López, Francisco Muñoz y Rafael Morales (1785), Gabriel Martínez (1786), Pedro Burniño (1787), Francisco Lucero (1788) y Francisco Núñez (1789).

13. Al respecto y contradiciendo parcialmente la representación del funcionamiento del fuerte en la documentación oficial, el análisis de las fuentes disponibles ha permitido identificar un documento sobre los asientos de los individuos en el fuerte San José, en el que se manda de 
regreso a un peón por haber encontrado a su mujer en dicho fuerte (AGN, Sala IX, 16-4-3 "J. Martínez a F. de Indarte, Puerto San José, 17 de agosto de 1786").

14. AGN, Sala X, 2-3-5 "A. Aragón al Comandante del fuerte del Carmen, 5 de septiembre de 1810". 15. A pesar de no haberse hallado aún información histórica sobre la parcialidad o parcialidades étnicas y los caciques que habrían encabezado el ataque, ha sido posible corroborar que los nombres de los caciques señalados como autores del ataque al fuerte San José, tanto en la obra de Barba Ruiz (2009) como en la placa conmemorativa colocada en la réplica de la capilla del fuerte, corresponden en realidad a un grupo de caciques mencionados por Entraigas (1968, p.22) que habrían atacado las instalaciones del fuerte, no en 1810, sino en los meses de julio y agosto de 1809. De acuerdo a Entraigas, dicha información fue obtenida en el Archivo General de la Nación -sin precisar mayor información-; sin embargo las exhaustivas pesquisas realizas por nuestro equipo de investigación no han podido dar con la supuesta documentación consultada por dicho autor.

16. Entraigas (1960 y 1968); De Paula (1984); Destéfani (1984); Dumrauf (1991 y 1992), Phillips (1962 en Gómez Otero, 2007 y Gavirati, 2012), D’Orbigny ([ca. 1835-1847] 1999), Fontana (1873), entre otros.

17. En Buscaglia s/f se puede encontrar una discusión extensa sobre los antecedentes reunidos respecto al ataque del fuerte San José y el Puesto de la Fuente por parte de los indígenas.

18. Si bien no alcanza el espacio aquí para desarrollar en extenso y reunir todos los relatos acerca del fin del fuerte San José, baste mencionar que el mismo caló tan profundo en la memoria de la región que reconocidos viajeros como el ya mencionado D'Orbigny ([ca. 1835-1847] 1999), Darwin [1839] 2003, Claraz ([1865-66] 1988) y Musters ([1871] 1997), no dejan de mencionarlo en sus crónicas sobre la Patagonia, varias décadas más tarde de ocurrido el episodio.

19. Un ejemplo emblemático de esta situación fue el motín que tuvo que afrontar Antonio Viedma como consecuencia de una epidemia de escorbuto en el fuerte San José a mediados de 1779 (Archivo General de Indias -en adelante AGI-, Legajo 326, folios 601-798, carta $\mathrm{n}^{\circ} 210$ "J. J. Vértiz a J. de Gálvez, Buenos Aires, 8 de octubre de 1779").

20. Por ejemplo se registra la queja por la recepción de tocino y grasa podridos (AGN, Sala IX, Legajo 16-4-12 “J. Maestre al Comandante de Puesto San José, sin lugar, 10 de enero de 1797").

21. AGN, Sala IX, 16-3-9 “J. A. Martínez a F. Viedma, Puesto del Puesto de San José, 14 de marzo de 1782 ".

22. Archivo General de Indias (en adelante AGI), Legajo 326, folios 601-798, carta $\mathrm{n}^{\circ} 210$ "J. J. Vértiz a J. de Gálvez, Buenos Aires, 8 de octubre de 1779".

23. AGN, Sala IX, 16-3-9 “A Juan Antonio Martínez, fuerte el Carmen Río negro, 2 de mayo de 1782"; 16-3-10 "Oficio de Don Juan Antonio Martínez a Don Francisco Viedma, fuerte San José, 7 de julio de 1782", "Juan José Gómez a Francisco Viedma, Puesto del Puerto San José, 24 de octubre de 1782"; 16-4-2 "Inventario de lo que subsiste en los almacenes de cuero que deja el Subteniente del Regimiento de Infantería de Buenos Aires Don Salvador José López..., F. Canales, Puerto San José, 27 de mayo de 1785"; "Inventario de lo que subsiste en los almacenes de cuero que deja el Teniente del Regimiento de Infantería de Buenos Aires Don Francisco Muñoz..., F. Canales, Puerto San José, 18 de noviembre de 1785"; 16-4-3 “S. J. López al Marqués de Loreto, Buenos Aires, 22 de julio de 1786", 16-4-6 "Florencio de Jesús a Tomás J. Gil, Puerto San José y fuerte de la Candelaria, 2 de mayo de 1789", "Florencio de Jesús a Tomás J. Gil, fuerte de la Candelaria Puerto San José, 22 de julio de 1789", "Marqués de Loreto al Comandante de Río Negro, 27 de noviembre de 1789"; 16-4-11 "Joaquín Maestre al Comandante del fuerte San José, 16 de enero de 1796, "Oficio de Don Juan Alejandro Pérez a Don Joaquín Maestre, Puerto de San José y fuerte de la Candelaria, 29 de enero de 1796", "Alejandro Pérez a Joaquín Maestre, Puerto San José y fuerte de la Candelaria, 2 de octubre de 1796", 16-5-1 “Oficio de Don Antonio Aragón a Don Joaquín Maestre, Puerto de San José y fuerte de la Candelaria, 14 de mayo de 1798”. AGN, Sala XIII, 26-6-6 “J. C. de Elguera a P. F. Indarte, fuerte Nuestra Señora del Carmen, 18 de diciembre de 1800", 31-1-5 “ Inventario de lo 
que subsiste en los almacenes de cuero que deja el Teniente de Regimiento de Infantería de Buenos Aires José Salazar..., Puerto San José, 18 de octubre de 1784", "Salvador José López, San José, 3 de febrero de 1785", "Salvador José López, San José, 19 de marzo de 1785", “Antonio García, Puerto de San José, 15 de octubre de 1785".

24. Ambas autoras han centrado sus investigaciones fundamentalmente en el análisis de la dinámica interétnica en el contexto del fuerte Nuestra Señora del Carmen. Por esta razón, los resultados de las mismas se constituyen en un excelente material a partir del cual comparar y complementar, sobre todo a partir de la evidencia arqueológica, los casos de Floridablanca y el fuerte San José.

25. Vértiz, J. J. [1778] 1938. Oficio del Virrey Vértiz del 3 de noviembre de 1778.

26. Vértiz a Gálvez, Montevideo 22 de febrero de 1783, AGI, Buenos Aires, 326.

27. Los intentos de evangelización a lo largo del siglo XVIII tuvieron un carácter más sistemático fuera de la costa patagónica, particularmente en las regiones de Pampa y el área andina de Norpatagonia (ver por ejemplo Urbina Burgos, 1990; Nicoletti, 2004; Néspolo, 2005; Irurtia, 2007 Arias, 2008; Hajduk, et al. 2013; Pedrotta, 2013, entre muchos otros).

28. Al respecto, es importante señalar el carácter fluctuante de las relaciones entre distintas comunidades indígenas, las que según las circunstancias eran amigas o enemigas (Nacuzzi, 2002).

29. Los ejemplos más destacados de los mismos son las capitulaciones y tratados de 1742, 1770, 1782, 1790 y 1796 establecidos entre funcionarios virreinales y los caciques más importantes de las distintas comunidades indígenas de Pampa y Patagonia, particularmente de la porción cordillerana y septentrional de la región. Tales tratados implicaban no solo el reconocimiento y la obediencia a la autoridad del rey de España sino también a sus representantes en territorio del virreinato. El poder colonial apeló a una estrategia de dominio indirecto -ya que se respetaba la autonomía y diversidad de las sociedades indígenas- pero no por ello menos coactivo, ya que en el mediano o largo plazo apuntaba al vasallaje de las mismas (Briones y Carrasco, 2000).

30. AGN, Sala IX, 16.3.2 "Carta de F. Viedma a J. J. Vértiz, fuerte Nuestra Señora del Carmen, 4 de junio de 1779"; Sala IX, 16.4.5 "Carta de F. Lucero a T. Gil (Capitán del Regimiento de Infantería de Buenos Aires y Gobernador de Río Negro), Puerto San José, 4 de junio de 1788"; “Carta de P. Burniño a T. Gil, fuerte del Carmen, 11 de junio de 1788" y Viedma [1783] 1972, entre otros.

31. AGN, Sala XIII, 34.10.5, 1780-1783, documentos varios.

32. Cabe agregar que para momentos posteriores sí se han registrado bienes y víveres para agasajar a indígenas en el contexto del fuerte San José (AGN, Sala X, 2-3-15 “F. de León, fuerte del Carmen, 20 de septiembre de 1809").

33. Estos 19 legajos integran un total de 91 y cerca de 11.768 folios relevados hasta la fecha en el marco del proyecto de investigación.

34. Archivo Histórico de Madrid, sección Estado, Legajo 2.316 "Diario de la expedición del mando del Comisario Superintendente Don Juan de la Piedra...".

35. Este dato es ampliado en el diario de Villarino de 1779, donde se consigna la deserción de 11 individuos del "pueblo" de San José. Asimismo manifiesta el conocimiento y el contacto con el cacique Julián Camelo y su gente, aunque las relaciones por momentos fueron conflictivas (AGN, Sala VII, Biblioteca Nacional, Legajo 193, “Diario de Basilio Villarino Bermúdez...”. Dicho diario fue publicado por De Angelis en forma apócrifa y sintética, que comparado con el original, presenta la información suministrada por el piloto de manera incompleta y en muchos casos inexacta (De Angelis, 1969, p.166-171).

36. Archivo Histórico de Madrid, sección Estado, Legajo 2.316 "Diario de la expedición del mando del Comisario Superintendente Don Juan de la Piedra...”.

37. AGN, Sala VII, Biblioteca Nacional, Legajo 193, "Diario de Basilio Villarino Bermúdez...".

38. De acuerdo a Carlos Gorla el envío de animales desde el Río Negro implicó un aumento de 13 a 64 vacunos y de 15 a 64 equinos en el período comprendido entre 1782 y 1784 . Entre 1786 y 1789 se observa un estancamiento y una declinación en la hacienda. A partir de ese año se 
incrementan las cabezas de ganado vacuno y equino hasta alcanzar el número de 400 y 108 respectivamente en 1798; existencias que irían en aumento hasta 1808 en que los indígenas se llevaron prácticamente toda la caballada y 600 vacunos (Gorla, 1983, p.136 y 161). Estas oscilaciones en la hacienda deberán ser correlacionadas con el abastecimiento desde Río Negro y las incursiones practicadas por los indígenas.

39. Fundação Biblioteca Nacional, MS-508 (40) Doc.1164 "Diario de la Expedición de Don José de Salazar al Puerto de San José, 1783".

40. Las relaciones con el cacique Negro son un claro ejemplo de la complejidad y ambivalencia que caracterizó a las relaciones interétnicas en la región pampeano-patagónica a fines del siglo XVIII. El cacique Negro por momentos se convirtió en aliado estratégico para Francisco Viedma y el fuerte Nuestra Señora del Carmen, en cuanto a la venta de tierras, el suministro de ganado y mano de obra indígena para avanzar en las obras del fuerte (D’Orbigny, A. ([1835-1847] 1999, p. 516-516). Sin embargo, en ocasiones fue concebido por el mismo Francisco Viedma como un enemigo que debía combatirse y aniquilarse, fundamentalmente por el robo de ganado y el maloneo en la frontera bonaerense (AGN, Sala IX, 16-3-6 "F. Viedma a J. J. Vértiz, fuerte del Carmen de Río Negro, 22 de marzo de 1781).

41. AGN, Sala IX, 16-3-16, "Antonio Viedma a Juan J. Vértiz, Nueva Colonia y fuerte de Floridablanca, 29 de enero de 1781".

42. AGN, Sala IX, 16-4-3, Informe sin fecha y lugar, 16-4-4, $1^{\circ}$ de octubre de 1787, Río Negro, sin remitente.

43. AGN, Sala IX, 16-4-4 "José Martínez a Ignacio de la Quintana, fuerte del Carmen, 14 de Junio de 1787 ".

44. AGN, Sala IX, 16-4-4 "Juan Mastorell, Buenos Aires, 18 de noviembre de 1787".

45. En esta oportunidad la embarcación solo tarda dos días en realizar el viaje de Río Negro a península Valdés.

46. AGN, Sala IX, 16-4-4, "Al Comandante de Río Negro, 3 de enero de 1787".

47. AGN, Sala IX, 16-4-4. "P. Burriño a J. I. de la Quintana, fuerte de la Candelaria en Puerto San José, 7 de agosto de 1787".

48. AGN, Sala IX, 16-4-4. "P. Burriño a J. I. de la Quintana, fuerte de la Candelaria en Puerto San José, 7 de agosto de 1787".

49. Los indios Rafael y Carlos, este último autor de la declaración, fueron llevados presos desde Río Negro a Buenos Aires en el mes de octubre de 1787 bajo la acusación de haber asesinado a un poblador y un soldado en el fuerte de Río Negro (AGN, Sala IX, 16-4-4 "Juan Mastorell, Buenos Aires, 18 de noviembre de 1787 y “J. I. de la Quintana, Río Negro, 28 de octubre de 1787).

50. AGN, Sala IX, 16-4-4 "Declaración tomada al Indio Carlos, alias Juancho, dependiente del Cacique Julián Camelo, por el Teniente de Infantería Lázaro Gómez... fuerte del Carmen, 2 de septiembre de 1787".

51. AGN, Sala IX, 16-4-4, "P. Burriño a J. I. de la Quintana, fuerte de la Candelaria en Puerto San José, 7 de agosto de 1787".

52. AGN, Sala IX, 16-4-5, “J. I. de la Quintana al Marqués de Loreto, fuerte del Carmen, 6 de abril de 1788 ".

53. Con respecto a estos dos caciques, solo se ha podido recabar información sobre Chulilaquini, sobre quien Francisco Viedma señalaba que dominaba una numerosa indiada en Norpatagonia, particularmente en las áreas adyacentes al río Negro, río Colorado, lago Nahuel Huapi y sur de Neuquén (Gorla, 1983; Nacuzzi, 1999 y 2005). Casamiquela, por su parte, identifica a Chulilaquini como un tehuelche septentrional cuyo nombre procedería del topónimo Chulila, la actual Cholila del noroeste de Chubut (1965 en Gorla, 1983).

54. AGN, Sala IX, 16-4-5 “T. Gil al Virrey J. J. Vértiz, fuerte del Carmen, 4 de junio de 1788.

55. AGN, Sala IX, 16-4-5 “F. Lucero a T. Gil, fuerte San José, 1º de junio de 1788”. 
56. AGN, Sala IX, 16-4-5 "Sumaria información hecha a fin de averiguar en quien recae la omisión de haber hecho fuga el diez de junio después de puesto el Sol, el Cacique Julián y otro Indio en la boca del Río Negro, desde el borde del Bergantín Nuestra Señora de la Piedad, que los conducía presos, y encargados el subteniente de Infantería de Buenos Aires, Don Bernardo Durán, por Don Francisco Lucero, teniente de dicho Regimiento y Comandante del Establecimiento de San José en la costa Patagónica, fuerte del Carmen, 11 de junio de 1788” y “T. Gil al Virrey Loreto, fuerte del Carmen, 20 de junio de 1788".

57. AGN, Sala IX, 16-4-5 “F. Lucero a T. Gil, Puerto de San José, 1º de junio de 1788".

58. AGN, Sala IX, 16-4-6 “T. Gil al Virrey Loreto, fuerte del Carmen, 24 de septiembre de 1789”.

59. AGN, Sala IX, 16-4-6 "Marqués de Loreto al Comandante del establecimiento de Río Negro, 27 de noviembre de 1789".

60. Es por lo menos llamativo que al comparar la documentación histórica referida a los asentamientos y las relaciones del grupo del cacique Julián con los mismos, poco se dice acerca del carácter excepcionalmente pacífico de sus relaciones con Floridablanca.

\section{ABSTRACTS}

In the late $18^{\text {th }}$ century, the Spanish Crown implemented the plan of colonization of the Patagonian Atlantic coast. As part of this plan, they created Nuestra Señora del Carmen Fort (Province of Buenos Aires), Nueva Colonia and Floridablanca Fort (Province of Santa Cruz), and San José Fort (Province of Chubut). My analysis will focus on the interethnic relations at San José Fort while discussing them as conveying foundational characteristics within a context of Bourbon and Indigenous contact policies, during the Fort's first decade. My results point to a particular structuring of interethnic relationships in San José Fort, showing a predominantly conflictive side as compared to the other two colonies.

A fines del siglo XVIII la Corona española pone en práctica el plan de colonización de la costa atlántica patagónica. Como parte del mismo fueron creados el fuerte Nuestra Señora del Carmen (provincia de Buenos Aires), la Nueva Colonia y fuerte de Floridablanca (provincia de Santa Cruz) y el fuerte San José (provincia de Chubut). En este trabajo me centraré puntualmente en el análisis de las relaciones interétnicas en el fuerte San José. En particular, me interesa contextualizar estas relaciones y discutirlas en función de las características inherentes a un contexto fundacional así como de las políticas indígenas y borbónicas respecto al contacto, durante la primera década de funcionamiento del fuerte. Los resultados obtenidos hasta el momento indican una estructuración particular de las relaciones interétnicas en el escenario del fuerte San José, manifestando una faceta predominantemente conflictiva, en comparación a los otros dos poblados.

\section{INDEX}

Keywords: San José Fort, Patagonia, Interethnic Relations, Colonialism, 18th Century

Palabras claves: fuerte San José, Patagonia, Relaciones Interétnicas, Colonialismo, Siglo XVIII. 


\section{AUTHOR}

\section{SILVANA BUSCAGLIA}

Instituto Multidisciplinario de Historia y Ciencias Humanas-Consejo Nacional de Investigaciones Científicas y Técnicas, Argentina.

Correo electrónico: silvana_buscaglia@yahoo.com.ar 